\title{
Revisiting status quo bias: Replication of Samuelson and Zeckhauser (1988)
}

\author{
*Qinyu Xiao \\ Department of Psychology, University of Hong Kong, Hong Kong SAR \\ xqy1020@hku.hk / xqyvincent@gmail.com \\ *Choi Shan Lam \\ Department of Psychology, Chinese University of Hong Kong, Hong Kong SAR \\ emmalam@link.cuhk.edu.hk / emmalam.413@gmail.com \\ *Muhrajan Piara \\ rajanpiara@gmail.com \\ $\wedge *$ Gilad Feldman \\ Department of Psychology, University of Hong Kong, Hong Kong SAR \\ gfeldman@hku.hk/giladfel@gmail.com
}

*Contributed equally, joint first author

${ }^{\wedge}$ Corresponding author

Word: abstract -144 , manuscript $-8,306$ 


\section{Corresponding author}

Gilad Feldman, Department of Psychology, University of Hong Kong, Hong Kong SAR; gfeldman@hku.hk.

\section{Author bios}

Gilad Feldman is an assistant professor with the University of Hong Kong psychology department. His research focuses on judgment and decision-making.

Qinyu Xiao is an M.Phil. student at the psychology department of the University of Hong Kong. Choi Shan Lam is an M.Phil. student at the psychology department of the Chinese University of Hong Kong.

Muhrajan Piara was a master's student at the Department of Health and Social Psychology at Maastricht University.

\section{Declaration of conflict of interest}

The authors declared no potential conflicts of interests with respect to the authorship and/or publication of this article.

\section{Financial disclosure/funding}

The authors received no financial support for the research and/or authorship of this article.

\section{Authorship declaration}

Gilad supervised each step in the project, conducted the pre-registrations, and ran data collection. Muhrajan Piara initiated the project, designed and analyzed the first phase of this replication project, as part of his masters dissertation. Choi Shan Lam reviewed and reanalyzed the first phase of the replication and then initiated, designed, and analyzed the data from the second phase. Qinyu Xiao reviewed the pre-registrations, verified all data analyses, and drafted the manuscript. Qinyu and Gilad finalized the manuscript for submission.

\section{Additional information}

The current replication is part of the larger "mass pre-registered replications in judgment and decision-making" project led by Gilad Feldman. The project aims to revisit well known research findings in the area of judgment and decision-making (JDM) and investigate the replicability of these findings. More information is available on: http://mgto.org/pre-registered-replications. 


\begin{abstract}
Status quo bias refers to people's general preference to stick to, or continue with, a previously chosen option. In two pre-registered experiments with U.S. participants recruited on the Amazon Mechanical Turk $\left(n_{1}=311, n_{2}=316\right)$, we attempted to replicate four decision scenarios (Question 1, 2, 4, and 6) from Samuelson and Zeckhauser (1988), the seminal article that provided the first experimental demonstration of the status quo bias. We found strong empirical support for the status quo bias in three decision scenarios out of the four, including budget allocation (Scenario 1/Question 1 in the original article), investment portfolios (Scenario 3/Question 2), and college job offers (Scenario 4/Question 4). However, we failed to find substantial support for the status quo bias in the wagon color choice scenario (Scenario 2/Question 6). We discuss the implications of our results and possible explanations using multiple accounts put forward in the status quo bias literature.
\end{abstract}

Keywords: status quo bias, judgment and decision making, replication 
Revisiting status quo bias:

Replication of Samuelson and Zeckhauser (1988)

\section{Introduction}

People tend to favor things as they are. The status quo bias refers to people's general tendency to stick with a previously chosen option in the face of other alternatives. In a seminal paper, Samuelson and Zeckhauser (1988) surveyed participants with hypothetical decision questions. They found that framing an option as the status quo resulted in a higher choice rate of that option, compared with framing it neutrally or as an alternative to the status quo (or nonstatus quo). Further supplementing the experimental results with field evidence, they demonstrated that a status quo bias is pervasive and profound in people's decision-making.

In this article, we report two attempts to replicate Samuelson and Zeckhauser (1988). Based on LeBel et al.'s (2018) criteria for evaluation of replications, we classified our experiments to be very close replications of the original study as they differed only in terms of physical settings and contextual variables (i.e., those that are beyond researchers' control; please refer to Figure $2 \mathrm{~S}$ and Table $12 \mathrm{~S}$ in the supplementary for details regarding the criteria and the classification). Our goal was to revisit these classic findings, to examine whether they withstand the test of time, and to accumulate further evidence to try and establish more precise effect size estimates (Nosek \& Lakens, 2014). We begin by introducing the literature on the status quo bias and the chosen article for replication, i.e., Samuelson and Zeckhauser (1988). We then highlight the motivation for the current replication study, present the results, and discuss their implications. 


\section{Status quo bias}

Samuelson and Zeckhauser (1988) were the first to demonstrate the status quo bias using controlled experiments. In part of their investigation, they presented a series of hypothetical decision-making scenarios and asked participants to choose among several available options. The scenarios and options came in two versions: in the neutral version, all options were presented equally as they were, without any framing, whereas in the status quo version (SQ), one option was framed as the status quo and the other options were reframed either as a change or in reference to the status quo option. The options were effectively the same in both versions.

Samuelson and Zeckhauser (1988) found that options were chosen more often when framed as the status quo, compared with when they were framed as an alternative to the status quo or without any framing. The status quo framing consistently led to the highest rate of choice, followed by the neutral framing and then by the non-status quo framing. Additionally, they showed that the preference for status quo options became more pronounced as the number of options increased (see also Tversky \& Shafir, 1992; Redelmeier \& Shafir, 1995).

People may sometimes be willing to continue with the status quo despite its lower utility compared to available alternatives (e.g., Suri et al., 2013). For instance, Samuelson and Zeckhauser (1988, p. 10) described a case where a small town in Germany was to be relocated due to a mining project. The authority offered the townspeople several planning options for the new town, which would be established at the authority's expense. Surprisingly, the townspeople opted for a plan quite much like that of the old town. The intricate layout of the old town that had evolved through centuries was unlikely to be efficient in modern times. Nonetheless, people chose it, arguably because of their preference for the status quo. Apparently, the status quo bias violates one of the foremost assumptions in rational decision-making theory that people aim to 
maximize expected utility and minimize loss (Tversky \& Kahneman, 1991). Should such an assumption have held, the townspeople would have been more than happy to see their new town be crafted with modern knowledge of city planning but not as a legacy of centuries' history.

The status quo bias challenges yet another, more specific assumption in rational decisionmaking models, which holds that only preference-relevant features matter in deciding among alternatives (Samuelson \& Zeckhauser, 1988). Economists once assumed that decision-making agents have well-defined, relatively stable preferences, and make choices accordingly (Kahneman et al., 1991). These preferences are determined by options' overall value for a decision maker (described with the umbrella term "utility") after they evaluated those features of their concern. Once preferences are set, the decision maker will go for the option with the highest expected utility, ignoring those preference-irrelevant variables. For instance, the order in which the options are presented or the labels they carry (e.g., a label of being the status quo) should not influence the decision maker's choice. Conversely, if we know a decision maker's choice among several options, we can confidently infer that the chosen option is of the highest expected value to, and hence preferred the most by, the decision maker. We can infallibly predict that the same option will be chosen regardless of, for example, how the available options are presented when there is no alternative with a higher expected value.

This assumption no longer holds in face of the status quo bias. Samuelson and Zeckhauser (1988) showed that the factor of being the status quo can drastically influence decision makers' choice patterns. An option chosen under the status quo framing may no longer be as preferred when framed as a non-status quo, despite that all options on the table remained essentially the same. The implications of their results are profound, if we consider how often in real life we 
make decisions where there is a status quo option. Arguably, continuing with the current choice or situation is almost always an option when there is a decision to make.

Indeed, empirical evidence so far suggests that the status quo bias has great influence in real life judgment and decision-making. Unlike the experiments by Samuelson and Zeckhauser (1988, Part One), where options became the status quo because they were so framed, studying the status quo bias in real life involved actual past choices. For instance, Samuelson and Zeckhauser (1988) went to the field to examine the choice of health insurance plans by Harvard employees and the allocation of retirement contributions to different funds by faculty throughout the U.S. Again, evidence pointed to a prominent status quo bias: Harvard employees tended to stick with the insurance plan they initially chose, despite the presence of a more attractive option. Teachers across the States tended to maintain one allocation ratio towards different retirement funds, though a change was easy and bore almost no cost. Similarly, Hartman et al. (1991) surveyed around 1,500 consumers in the U.S. on the reliability and rate of their electricity service. The researchers found that around 60 percent households, regardless of the actual reliability of the services they received, indicated that they preferred the status quo the most (p. 149). Johnson and colleagues (1993) looked into the automobile insurance industry in New Jersey and Pennsylvania, where different status quos were present. They found that when given an option to lower insurance rates by reducing the right to sue, $75 \%$ of Pennsylvanians chose to retain their full right; in contrast, when given an option to obtain the full right to sue by paying higher rates, only $20 \%$ of those in New Jersey chose that option (p. 48). These studies have provided strong evidence for the pervasiveness of the status quo bias in the real world.

The status quo bias has been a handy tool in explaining many social phenomena. For instance, Samuelson and Zeckhauser (1988, p. 9) linked the bias to incumbent office holders' 
advantage in elections (see Cox \& Morgenstern, 1993; Erikson, 1971; Muthukrishnan, 1995). Based on their estimation, an incumbent officer would claim a 59 over 41 percent victory if the officer and a competitor were equally preferred without incumbency. In marketing, a wide range of soft-selling techniques make use of the status quo bias. Experienced marketers often induce consumers into what is called a trial purchase (Thaler, 1980), where the product can later be returned with full refund. Though a free trial appears to impose no loss to consumers, it becomes the status quo that the consumers will later find it hard to live without and, therefore, give up the refundable payment to continue their ownership of the item. Also, the status quo bias may play a role in brand loyalty (Shi et al., 2018) and pioneering, or first-mover, advantages, i.e., first entrants into a market obtain long-term market share advantages over followers (Kleiser \& Wagner, 1999; Lieberman \& Montgomery, 1988). Apart from marketing studies, research has also explored the bias in mating choices (Gunaydin et al., 2018) and technological reforms (Montpetit \& Lachapelle, 2017).

From a broader perspective, the status quo bias may also explain why public policy making is sluggish (Atkinson, 2011) and scientific progress is more like a series of revolutions rather than an incremental accumulation of small advances (Kuhn, 2012). New policies are hard to establish, and old ones are hard to abolish. A well-received scientific paradigm could dominate researchers' attention and resources for years and even decades. In sum, our evidence and theoretical conjectures imply that the status quo bias is pervasive in economic, scientific, social, and cultural decision-making situations.

\section{Explaining the status quo bias}

Numerous accounts have been put forward to explain the status quo bias. They fall roughly into two types. Some attempted to accommodate the bias into a rational decision-making 
framework, arguing that the seemingly irrational preference for the status quo option can be consistent with the goal of utility maximization or accounted for axiomatically without appealing to psychology-based explanations (e.g., Dupont \& Lee, 2002; Masatlioglu \& Ok, 2005; Nebel, 2015). Others appealed to a series of non-rational psychological mechanisms in explaining the status quo preference, such as heuristics, biases, and misperceptions (Eidelman \& Crandall, 2012; Samuelson \& Zeckhauser, 1988; see also Anderson, 2003). We briefly introduce some of these accounts, beginning with those deeming the preference for the status quo rational.

\section{Rational accounts}

For those who consider the status quo bias rational, people exhibit this "bias" simply because their preferences have not changed, they find switching to a non-status quo costly, or they feel uncertain about the outcome of switching (Anderson, 2003; Nebel, 2015). One major reason why people resist changes in real life is the cost associated with transitions. Such cost may be trivial in deciding which dishes to order, but can be overwhelming in cases of changing jobs, moving home, and implementing new public rules (Iyengar \& Lepper, 2000). If alternatives do not show clear superiority, people are likely to stick with the status quo as it is normally easier to do so and it incurs predictable costs.

Decision makers often do not have complete information about available choices, and a thorough analysis of their pros and cons may at times be costly and impractical, even impossible in some cases (Gigerenzer \& Selten, 2002; Lieder \& Griffiths, 2020). On such occasions where decision makers have a high degree of uncertainty, maintaining the status quo is a safe and hence rational choice (Samuelson \& Zeckhauser, 1988). If an option has worked out in the past, one could reasonably expect it to also work out in the future; if an option has been chosen by one in the past, the person could reasonably assume that the choice has passed his or her inspection, and 
possibly many others' (Eidelman \& Crandall, 2012). As Samuelson and Zeckhauser (1988) pointed out, people commonly use a cut-off strategy in decision-making: as long as the current option is good enough (Simon, 1956), there is no impetus to run an arduous analysis of alternatives and initiate a change. A satisficing strategy, i.e., stay with a sufficiently good option rather than continuously look for the best, can be rational in an uncertain world (Schwartz et al., 2002, 2011).

Subsuming the preference for the status quo within the rational decision-making framework, these accounts are plausible but may be insufficient. For example, Samuelson and Zeckhauser (1988) explicitly ruled out transitional costs in the descriptions of their hypothetical decision-making scenarios and still observed consistent and pervasive status quo bias. Also, with respect to the account that appeals to decision makers' limited information, the scenarios, however, did not present more details for the status quo option than the alternatives. Apart from the framing, these options were comparable in terms of the amount of information they carried.

Participants might, however, have assumed that they knew more about the status quo. For instance, for Question 4 in Samuelson and Zeckhauser (1988), participants chose from different college job offers. They were employed by one of the colleges if they received the status quo version of the question. This could have led participants to think that they knew more about their current workplace than the alternatives (e.g., in terms of colleagues) and hence choose it due to factors unspecified in the choice descriptions. Nonetheless, such considerations were not as prominent in the other questions in the study, and it was unlikely that participants really read these considerations into their decision-making processes, as they were not motivated to do so (Samuelson \& Zeckhauser, 1988, p. 9). Overall, rational accounts fall short in explaining the status quo bias on their own. 


\section{Non-rational accounts}

The status quo bias has been linked to loss aversion, a cognitive misperception whereby people weigh losses more than equal gains (Tversky \& Kahneman, 1991; Mrkva et al., 2020). Because of this misperception, when faced with a decision involving risk, people tend to riskavoidant if decision outcomes are framed as gains and risk-seeking if the same outcomes are framed as losses (Tversky \& Kahneman, 1981). To explain the status quo bias with loss aversion, consider the situation where one decides between two different but similarly appealing options. Given that they are different but have similar levels of appeal, choosing either of them implies gains in some respects and losses in some others, and they cancel out. However, if one option is made the status quo and one takes that option as a reference point, the losses of switching to the other option would outweigh the gains because of loss aversion (Moshinsky \& Bar-Hillel, 2010; see also Thaler, 1980). Consequently, switching is unlikely if no option shows a clear advantage. Loss aversion per se can explain the status quo bias in the case of multiple similarly attractive options.

Researchers have invoked heuristics and several other biases to account for the preference for the status quo, such as anchoring, the longevity and existence biases, and the mere exposure effect (Eidelman \& Crandall, 2012; Samuelson \& Zeckhauser, 1988). Anchoring refers to the phenomenon that people's judgments are biased towards initially presented values (Ariely et al., 2003; Tversky \& Kahneman, 1974). For instance, Ariely and colleagues (2003) observed a positive correlation between participants' social security numbers, which the researchers explicitly asked for during an experiment, and the minimal prices they would like to pay for a bottle of wine (replicated in Bergman et al., 2010; but challenged by Fudenberg et al., 2012; Maniadis et al., 2014). Samuelson and Zeckhauser (1988) argued that the same phenomenon 
underlies the status quo bias, particularly with respect to decision questions with continuous options, e.g., Question 7 and 8 in their study.

The existence and longevity biases refer to people's unthinking assumption that existing and longstanding things are good (Eidelman et al., 2009, 2010). They are thought to underlie the status quo bias (Eidelman \& Crandall, 2012, 2014): we maintain the status quo simply because it already exists and outlasts other alternatives. In addition, an option being the status quo increases its likelihood and frequency of being exposed to the decision maker, and makes the person like the option more due to the mere-exposure effect (Eidelman \& Crandall, 2014; Zajonc, 1968). Although interrelated, exposure effect and existence and longevity biases may work independently in leading to a status quo preference. People need not infer existence and longevity from exposure, and existence alone does not necessarily entail more exposures (Eidelman \& Crandall, 2012, 2014).

On top of biases and heuristics, people are also motivated to continue with and even to defend the status quo. Cognitive dissonance theory predicts that maintaining conflicting ideas or stances simultaneously is hard, and people strive continuously for consistency among their beliefs and behaviors (Festinger, 1962; Festinger \& Carlsmith, 1959). Past choices can be informative of one's preferences (self-perception theory, e.g., Bem, 1972) and individuals are inclined to find or even fabricate reasons in support of, i.e., rationalize, their decisions (Brehm, 1956; Eyster, 2002; Eidelman \& Crandall, 2014). Collectively, these factors drive people to stick with status quo options and even find them reasonable, desirable, and just (Jost et al., 2004; Kay et al., 2009) so that the validity of their reasoning is affirmed, and the consistency between their beliefs and behaviors gets maintained. 
In addition, emotions, particularly regret, may play a role in the status quo bias. Research so far has suggested that people experience greater regret when their decision changes the status quo than maintains it if the decision results in undesirable outcomes; relatedly, people are more aversive of errors of commission than of errors of omission (Ritov \& Baron, 1992; cf. Inman \& Zeelenberg, 2002; but see Connolly \& Zeelenberg, 2002 for the role of justification).

Consequently, people tend to opt for the status quo to avoid potential regret. A separate line of research has found that positive moods are associated with higher magnitudes of status quo bias, suggesting that people may stick with the status quo so as to prolong a desirable mental state (Shevchenko et al., 2014; Yen \& Chuang, 2008). In addition to material transition costs, contemplating about a change and available options incurs mental costs, which often manifest as negative emotions, e.g., fear and anxiety, which are collectively termed as anticipatory emotions (Loewenstein et al., 2001; Anderson, 2003). Decision makers can avoid such emotions by choosing the status quo, particularly when the trade-offs are difficult to make (per the trade-off avoidance hypothesis, see Luce, 1998; Luce et al., 1997). Unless sufficiently motivated, the decision maker may even refrain from contemplating about a change at the first place, in line with organisms' general tendency to conserve their energy (Anderson, 2003).

There is no merit in thinking that any of the abovementioned factors explains the status quo bias on its own. It is much more likely that multiple mechanisms combined leads to the preference for the status quo. We still face the critical task of determining the attributes of the options, the context of decisions, as well as individual differences, etc. that enhance, mitigate, or even eliminate the bias and ideally, the respective weights of these factors.

One final note concerning the status quo bias: The bias is often discussed along with other conceptually similar behavioral findings, such as the omission bias (preference for inaction over 
action; Ritov \& Baron, 1992; Baron \& Ritov, 1994), inaction inertia (initial inaction persists; Tykocinski et al., 1995; Tykocinski \& Pittman, 1998), as well as choice deferral (Dhar, 1996). These behavioral findings have common underlying mechanisms and are collectively captured as decision avoidance (Anderson, 2003). Nonetheless, their concepts are not the same and hence cannot be used interchangeably (Feldman et al., 2020), and some evidence has shown that they operate independently (Schweitzer, 1994; Baron \& Ritov, 1994).

\section{Choice of study for replication}

We chose Samuelson and Zeckhauser's (1988) study as our replication target for two reasons: its impact and the absence of direct replications. The article was one of the earliest and most cited works on the status quo bias, with over five thousand Google Scholar citations at the time of writing. And there have been many important follow-up empirical and theoretical works, such as Kahneman et al.'s (1991) work that linked the status quo bias to people's tendency to weigh losses more than gains (i.e. loss aversion). Despite its impact, to the best of our knowledge, there have been no published pre-registered direct replications of this study thus far.

The real-world implications of the status quo bias are profound. The bias may explain many social phenomena relevant to judgment and decision making, and additionally it may well be a critical factor to consider when people are to make important decisions. A carefully chosen status quo may have a great social impact to the extent that it may save the lives of thousands (Abadie \& Gay, 2006; Johnson \& Goldstein, 2003).

We therefore aimed to revisit this classic phenomenon to examine the replicability of the original findings with independent replications. Although Samuelson and Zeckhauser's (1988) results supported a status quo bias overall, the bias seemed less prominent for some options and 
in some of their decision-making scenarios than in others. By replicating this classic study, we hoped to examine whether such effect size differences were random in nature. If not, there could be something inherent to the decision questions that determine the extent to which decision makers exhibit the preference for the status quo. The replication attempts also answer calls in the recent growing recognition of the importance of reproducibility and replicability in psychological science (Brandt et al., 2014; Open Science Collaboration, 2015; van 't Veer \& Giner-Sorolla, 2016; Zwaan et al., 2018), as well as the importance of orienting towards effect sizes and adopting a meta-analytic thinking in our scientific endeavors (Cumming, 2014). We therefore embarked on a well-powered, pre-registered close replication of Samuelson and Zeckhauser (1988).

\section{Original findings in target article}

The target article reported a consistent pattern of results across decision-making scenarios that an option was chosen more often when it was framed as the status quo, compared to when it was framed as a non-status quo option or without any framing. In addition, an option was more likely to be chosen if it was framed neutrally than it was framed as a non-status quo option. This pattern was present for 17 out of the 24 options in the six four-option decision questions used in the target article. The choice rates of 14 options were significantly higher when they were the status quo than when they were alternatives to the status quo based on an alpha level of .05.

We followed the target article to conduct independent-proportions tests to compare the choice rates of options as the status quo and as a non-status quo. Samuelson and Zeckhauser (1988) did not report whether there were statistically significant differences in choice rates between status quo options and options under a neutral framing. We tested these and reported the 
results in the supplementary (Table $3 \mathrm{~S}$ ), since this is a stricter test for the status quo bias. Our hypotheses, therefore, were:

$\mathrm{H}_{1}$ : Options have higher choice rates when framed as the status quo than as a non-status quo, i.e., an alternative to the status quo. This hypothesis was tested in the target article, and $p$-values were reported.

$\mathrm{H}_{2}$ : Options have higher choice rates when framed as the status quo than when neutrally framed (i.e., no option is the status quo). The target article did not test this hypothesis with any significance testing procedure.

A summary of the original findings that were relevant to our replication has been provided in Table $2 \mathrm{~S}$ and Table $3 \mathrm{~S}$ in the supplementary. For 10 out of the 16 options that were included in our replications, the choice rate under a status quo framing was significantly higher than that under a non-status quo framing. For 11 options, the choice rate under a status quo framing was higher (in the descriptive sense) than that under a neutral framing, which was in turn higher than that under a non-status quo framing.

We also conducted post hoc power analyses and sensitivity analyses for the original study, focusing on the comparison between the status quo framing and the non-status quo framing (i.e., $\mathrm{H}_{1}$; refer to the supplementary for details, particularly Table $4 \mathrm{~S}$ and $5 \mathrm{~S}$ ). Our analysis indicated that the post hoc power ranged from .08 to over .99 , with an average of .57 across the 16 options. The achieved power varied greatly even within the scenarios, suggesting that the effect size estimations were not very precise and the original study was insufficiently powered to provide consistent effect size estimations (note that post hoc power should be interpreted very cautiously, if at all; see Gelman, 2019). Our sensitivity analyses revealed that the original tests for $\mathrm{H}_{1}$ (i.e., 
two-tailed independent-proportions tests) were powered at .80 to detect, on average, a Cohen's $h$ of 0.58, a medium-to-large effect by Cohen's (1988) benchmarks. Nevertheless, if we looked at the 16 options individually, the test for some options could only detect Cohen's $h$ over 0.70 at .80 power. Overall, the original study may not have been sufficiently powered.

\section{Overview of replication}

The current replications focused on Questions 1, 2, 4, and 6 in Part One of Samuelson and Zeckhauser's (1988, Appendix) original questionnaire (Question 3, 5, 7, and 8 in Part One of the original study were not used here. Question 7 and 8 were of a different kind in the sense that participants chose from a continuum of possible options. Part Two of the original study investigated whether the status quo bias would emerge when participants made sequential choices). The first-phase replication focused on Questions 1 and 6, and the second-phase replication focused on all four questions. We chose to conduct the replication on this subset to focus on the simplest demonstrations of status quo effect by framing, meet time and resource constraints, and minimize burden on participants in our target samples that is sensitive to task duration.

For each decision question, participants were either presented with a neutral version or a status quo version. In the neutral version, options were presented without any framing, whereas in the status quo version, one option was framed as the status quo, and other options were reframed with reference to the status quo option or as a change. The target study used two-option, three-option, as well as four-option versions for each of the decision questions. We used only the four-option version in our replications due to online survey administration time constraints, and for simplifying the design without looking into the number of options as a possible moderating factor. 


\section{Pre-registration and open science}

We pre-registered our experiments on the Open Science Framework (OSF) and data collection was launched after that. Pre-registrations, power analyses, and all materials used in these experiments have been shared on the OSF (project page: https://osf.io/kh8q3; first-phase pre-registration: https://osf.io/c3phs; second-phase pre-registration: https://osf.io/69hzx). Full open-science details and disclosures are provided in the supplementary. All measures, manipulations, exclusions conducted for this investigation have been reported and shared.

\section{Method}

\section{Participants}

A total of $311\left(M_{\text {age }}=38.05, S D=12.38 ; 164(52.7 \%)\right.$ females $)$ and $316\left(M_{\text {age }}=38.79, S D\right.$ $=11.67 ; 161$ (50.9\%) females) Amazon Mechanical Turk (MTurk) participants completed the first and the second phases of our replication experiments, respectively. There was a one-year time lag between the two data collections. The second data collection was meant to verify results from first data collection, extend the number of scenarios, and improve on technical issues such as introducing randomized presentation order of the scenarios. A comparison of original sample and the replication samples has been provided in Table $6 \mathrm{~S}$ and $7 \mathrm{~S}$ in the supplementary. We preregistered our power analyses and reported that we aimed at 300 participants in the preregistrations. Nonetheless, as one reviewer pointed out, the power analyses were inadequate. Therefore, we conducted an additional "post hoc" (i.e., after data collection) power analysis, which suggested that we needed 355 participants to detect a Cohen's medium effect at .95 power with the planned tests. Although we did not meet this number, our sample sizes were close and may therefore be considered adequate power for these replications. We reported the full sample 
results here in the main text. For results after exclusion, please refer to Table $8 \mathrm{~S}$ to $11 \mathrm{~S}$ in the supplementary. There were no major discrepancies between these results. Apart from exclusion based on our pre-registered criteria, we also excluded part of the data as after data collection we found an error in the questionnaire used in the second-phase replication (see supplementary error documentation for details).

\section{Design and procedure}

The experiments followed a between-subjects design, and the design was the same in both phases of replication. Four decision questions (Question 1, 6, 2, and 4, referred to as Scenarios 1 to 4 in our replications) were adopted from Samuelson and Zeckhauser (1988). The order of presentation was fixed in the first phase but randomized in the second phase (there was no sign that this variation had any major influence on the results). These questions asked participants to evaluate and decide among (1) budget allocation ratios for safety research programs, (2) color options for a wagon that one just purchased, (3) investment portfolios, and (4) college job offers. Each question had four options. Participants in the first-phase replication answered Scenario 1 and 2 only, whereas those in the second phase answered all four scenarios.

\section{Manipulations}

Each scenario was presented in one out of five versions: one neutral version and four status quo versions. In the neutral version, no option was the status quo. In the status quo versions, one of the four options was framed as the status quo, i.e., as a previously chosen or the default option. Participants were randomly presented with only one version for each scenario.

Take Scenario 1 as an example. This scenario was about different budget allocation ratios for safety research programs. The below was the neutral version: 
The National Highway Safety Commission is deciding how to allocate its budget between two safety research programs: (1) improving automobile safety (bumpers, body, gas tank configurations, seat-belts), and (2) improving the safety of interstate highways (guard rails, grading, highway interchanges, and implementing selective reduced speed limits). Since there is a ceiling on its total spending, it must choose between the options provided below. If you had to make this choice, which of the following will you choose?

And the four options for the neutral version were:

a. Allocate $70 \%$ to auto safety and $30 \%$ to highway safety.

b. Allocate $30 \%$ to auto safety and $70 \%$ to highway safety.

c. Allocate $60 \%$ to auto safety and $40 \%$ to highway safety.

d. Allocate $50 \%$ to auto safety and $50 \%$ to highway safety.

One status quo version for Scenario 1, where the "70A30H" option (Option A above) was

framed as the status quo, was as below:

The National Highway Safety Commission is deciding how to allocate its budget between two safety research programs: (1) improving automobile safety (bumpers, body, gas tank configurations, seat-belts), and (2) improving the safety of interstate highways (guard rails, grading, highway interchanges, and implementing selective reduced speed limits). Currently, the commission allocates approximately $70 \%$ of its funds to auto safety and $30 \%$ of its funds to highway safety. Since there is a ceiling on its total spending, it must choose between the options provided below. If you had to make this choice, which of the following will you choose?

The options in this status quo version were:

a. Maintain present budget amounts for the programs.

b. Decrease auto program by $10 \%$ and raise highway program by like amount.

c. Decrease auto program by $40 \%$ and raise highway program by like amount.

d. Decrease auto program by $20 \%$ and raise highway program by like amount.

The display order of the options was randomized.

All versions of scenario descriptions were followed by a few comprehension questions to ensure that participants read and understood the texts. Particularly, for the status quo versions, participants were additionally asked what the status quo was. They had to answer these 
comprehension questions correctly before proceeding to see the options and make their choices. This design was meant to address participants' inattentiveness. The median response time for each of the scenarios in the two phases ranged from 19.67 seconds to 31.07 seconds. Since the participants had already read the scenario descriptions before the options were presented (i.e., most of the response time reported above was used to read the options only), we consider this time sufficient for participants to make informed decisions rather than random choices. We provided the response time descriptives in our analysis files for interested readers.

With the version manipulation, each option could take three positions: as the status quo option in one status quo version, as a non-status quo option in three other status quo versions, or as a neutral option in the neutral version. Participants saw any option under only one framing, in accordance with the between-subjects design of the experiment.

\section{Replication evaluation}

As noted at the beginning, we summarized our replications as very close replications using the criteria set by LeBel et al. (2018). We aimed to compare the replication effects with the original effects using the criteria set by LeBel et al. (2019) (Figure 1S). 


\section{Results}

\section{First phase}

We summarized the descriptive statistics (i.e., counts and proportions) and analysis results of the first-phase replication in Table 1 and 2. This phase tested Scenarios 1 and 2. We found a consistent pattern in Scenario 1 that an option was chosen more often when it was the status quo than when it was neutrally framed. In addition, options were the least likely to be chosen when they were alternatives to the status quo. This pattern, however, did not emerge in Scenario 2.

Independent-proportions tests were conducted to compare choice rates between the status quo and non-status quo framing, and between the status quo and the neutral framing. The options in Scenario 1 had significantly higher choice rates as the status quo than as a non-status quo, $\chi^{2} \geq$ 9.38, $p \mathrm{~s} \leq .002$, smallest odds ratio $=2.47,95 \%$ CI $[1.37,4.44]$, smallest Cohen's $h=0.44,95 \%$ CI $[0.16,0.73]$. The effect sizes were around medium $(0.5)$ by Cohen's benchmarks (Cohen, 1988). Comparing the choice rates of options under the status quo framing and the neutral framing, we found, however, one non-significant difference (for the option " $30 \mathrm{~A} 70 \mathrm{H}$ "), $\chi^{2}=$ $1.10, p=.294$, odds ratio $=1.46,95 \%$ CI $[0.72,2.97]$, Cohen's $h=0.19,95 \%$ CI [-0.16, 0.54]. The other three difference were statistically significant, $p \mathrm{~s} \leq .033$, and the effect sizes ranged from 2.16 to 4.83 in odds ratio or 0.38 to 0.57 in Cohen's $h$. Overall, our data provided strong support for the status quo bias (both $\mathrm{H}_{1}$ and $\mathrm{H}_{2}$ ) in Scenario 1.

We found weak-to-no support for the status quo bias, or $\mathrm{H}_{1}$ and $\mathrm{H}_{2}$, in Scenario 2. Comparing the status quo framing with the non-status quo framing, we observed no significant differences in the expected direction, $\chi^{2} \leq 2.56, p \mathrm{~s} \geq .110$. Comparing the status quo framing with the neutral framing, only one option (white) had a significant difference in the expected direction, 
$\chi^{2}=5.06, p=.024$, odds ratio $=2.81,95 \%$ CI $[1.12,7.07]$, Cohen's $h=0.41,95 \%$ CI $[0.06$, 0.76].

Table 1. Status quo vs. non-status quo ( $1^{\text {st }}$ phase $)$

\begin{tabular}{|c|c|c|c|c|c|c|c|c|}
\hline \multirow[b]{2}{*}{ Options } & \multicolumn{3}{|c|}{ Choice rates } & \multicolumn{5}{|c|}{ Status quo vs. non-status quo } \\
\hline & SQ & $\mathbf{N}$ & NSQ & $\chi$ & & $p$ & $\begin{array}{l}\text { Odd ratio } \\
\text { (95\% CI) }\end{array}$ & $\begin{array}{l}\text { Cohen's } h \\
(95 \% \text { CI }\end{array}$ \\
\hline \multicolumn{9}{|c|}{ Scenario 1: budget allocation ratios } \\
\hline $70 \mathrm{~A} 30 \mathrm{H}$ & $18 / 62(.29)$ & $5 / 64(.08)$ & $12 / 185(.06)$ & 22.12 & $<.001$ & 5.90 & $4,13.15]$ & $0.62[0.34,0.91]$ \\
\hline $30 \mathrm{~A} 70 \mathrm{H}$ & $30 / 60(.50)$ & $26 / 64(.41)$ & $45 / 187(.24)$ & 14.45 & $<.001$ & 3.16 & $2,5.79]$ & $0.55[0.25,0.84]$ \\
\hline $60 \mathrm{~A} 40 \mathrm{H}$ & $24 / 63(.38)$ & $10 / 64(.16)$ & $23 / 184(.12)$ & 19.95 & $<.001$ & 4.31 & $0,8.42]$ & $0.61[0.32,0.89]$ \\
\hline $50 \mathrm{~A} 50 \mathrm{H}$ & $34 / 62(.55)$ & $23 / 64(.36)$ & $61 / 185(.33)$ & 9.38 & .002 & 2.47 & $7,4.44]$ & $0.44[0.16,0.73]$ \\
\hline \multicolumn{9}{|c|}{ Scenario 2: wagon colors } \\
\hline Red & $8 / 62(.13)$ & $14 / 63(.22)$ & $26 / 186(.14)$ & 0.05 & .831 & 0.91 & $9,2.13]$ & $-0.03[-0.32,0.26]$ \\
\hline Silver Blue & $35 / 62(.56)$ & $37 / 63(.59)$ & $108 / 186(.58)$ & 0.05 & .824 & 0.94 & $2,1.671$ & $-0.03[-0.32,0.25]$ \\
\hline Tan & $4 / 62(.06)$ & $4 / 63(.06)$ & $13 / 186(.07)$ & 0.02 & .885 & 0.92 & $9,2.93]$ & $-0.02[-0.31,0.27]$ \\
\hline White & $18 / 62(.29)$ & $8 / 63(.13)$ & $36 / 186(.19)$ & 2.56 & .110 & 1.70 & $8,3.29]$ & $0.23[-0.06,0.51]$ \\
\hline
\end{tabular}

Table 2. Status quo vs. neutral ( $1^{\text {st }}$ phase)

\begin{tabular}{|c|c|c|c|c|c|c|c|}
\hline \multirow[b]{2}{*}{ Options } & \multicolumn{3}{|c|}{ Choice rates } & \multicolumn{4}{|c|}{ Status quo vs. neutral } \\
\hline & SQ & $\mathbf{N}$ & NSQ & $\chi^{2}$ & $p$ & $\begin{array}{l}\text { Odd ratio } \\
(95 \% \text { CI })\end{array}$ & $\begin{array}{l}\text { Cohen's } h \\
(95 \% \text { CI) }\end{array}$ \\
\hline \multicolumn{8}{|c|}{ Scenario 1: budget allocation ratios } \\
\hline $70 \mathrm{~A} 30 \mathrm{H}$ & $18 / 62(.29)$ & $5 / 64(.08)$ & 12/185 (.06) & 9.50 & .002 & $4.83[1.66,14.00]$ & $0.57[0.22,0.92]$ \\
\hline $30 \mathrm{~A} 70 \mathrm{H}$ & $30 / 60(.50)$ & 26/64 (.41) & 45/187 (.24) & 1.10 & .294 & $1.46[0.72,2.97]$ & $0.19[-0.16,0.54]$ \\
\hline $60 \mathrm{~A} 40 \mathrm{H}$ & $24 / 63(.38)$ & $10 / 64(.16)$ & $23 / 184(.12)$ & 8.18 & .004 & $3.32[1.43,7.74]$ & $0.52[0.17,0.87]$ \\
\hline $50 \mathrm{~A} 50 \mathrm{H}$ & $34 / 62(.55)$ & 23/64 (.36) & $61 / 185(.33)$ & 4.54 & .033 & $2.16[1.06,4.42]$ & $0.38[0.03,0.73]$ \\
\hline \multicolumn{8}{|c|}{ Scenario 2: wagon colors } \\
\hline Red & $8 / 62(.13)$ & $14 / 63(.22)$ & 26/186 (.14) & 1.87 & .171 & $0.52[0.20,1.34]$ & $-0.25[-0.60,0.10]$ \\
\hline Silver Blue & $35 / 62(.56)$ & $37 / 63(.59)$ & $108 / 186(.58)$ & 0.07 & .797 & $0.91[0.45,1.85]$ & $-0.05[-0.40,0.30]$ \\
\hline Tan & $4 / 62(.06)$ & 4/63 (.06) & $13 / 186(.07)$ & 0.00 & .981 & $1.02[0.24,4.26]$ & $0.00[-0.35,0.35]$ \\
\hline White & $18 / 62(.29)$ & $8 / 63(.13)$ & $36 / 186(.19)$ & 5.06 & .024 & $2.81[1.12,7.07]$ & $0.41[0.06,0.76]$ \\
\hline
\end{tabular}

Note. $\mathrm{SQ}=$ status quo, $\mathrm{N}$ = neutral, $\mathrm{NSQ}=$ non-status quo. 


\section{Second phase}

We summarized the descriptive statistics and analysis results of the second-phase replication in Table 3 and 4. We observed the hypothesized pattern (i.e., the choice rate of an option is the highest under the status quo framing and the lowest under the non-status quo framing) in 12 out of the 16 options in the four scenarios (the exceptions were: " $30 \mathrm{~A} 70 \mathrm{H}$ " in Scenario 1; silver blue and white in Scenario 2; and College D in Scenario 4).

Again, we conducted independent-proportions tests for our $\mathrm{H}_{1}$ and $\mathrm{H}_{2}$. The status quo framing resulted in significantly higher choice rates for nearly all options in Scenario 1, regardless of whether it was compared against the non-status quo framing $\left(\chi^{2} \geq 10.81, p \mathrm{~s} \leq .001\right.$, lowest odds ratio $=2.78,95 \%$ CI $[1.49,5.17]$, lowest Cohen's $h=0.46,95 \%$ CI $[0.17,0.74])$ or against the neutral framing (for the significant differences: $\chi^{2} \geq 4.97, p s \leq .026$, lowest odds ratio $=2.40,95 \%$ CI $[1.10,5.21]$, lowest Cohen's $h=0.40,95 \%$ CI $[0.05,0.74])$. The only exception was the " $50 \mathrm{~A} 50 \mathrm{H}$ " option, for which the comparison between the status quo framing and the neutral framing did not result in a significant difference, $\chi^{2}=2.64, p=.104$; yet the effect was in the predicted direction, odds ratio $=1.79,95 \%$ CI $[0.88,3.64]$, Cohen's $h=0.29,95 \%$ CI $[-0.06$, 0.64].

Although most options in Scenario 3 and 4 exhibited the hypothesized pattern, the results of our independent-proportions tests failed to consistently meet the se statistical significance criteria. There was only one option (College C in Scenario 4) for which both comparisons (i.e., status quo vs. non-status quo and status quo vs. neutral) yielded statistically significant differences. There were two options (Moderate Risk and High Risk in Scenario 2) for which both differences were not significant. Comparing the status quo framing with the non-status quo framing, the effect sizes ranged from 1.66 to 3.15 in odds ratio or 0.16 to 0.47 in Cohen's $h$ in 
Scenario 3, and from 1.81 to 4.88 in odds ratio or 0.27 to 0.75 in Cohen's $h$ in Scenario 4.

Comparing the status quo framing with the neutral framing, the effect sizes ranged from 1.31 to 1.85 in odds ratio or 0.09 to 0.31 in Cohen's $h$ in Scenario 3, and from 1.75 to 3.26 in odds ratio or 0.23 to 0.58 in Cohen's $h$ in Scenario 4. Despite the non-significant differences, our data still provide good support overall for the status quo bias in these two scenarios. The bias seemed to be more pronounced in Scenario 4 than in 3 based on the observed effect sizes.

Like in the first-phase replication, we found the least support for the status quo bias in Scenario 2. Two options did not exhibit the hypothesized pattern. For silver blue, the non-status quo framing even led to higher choice rate than the status quo framing. Comparing the status quo framing with the non-status quo framing, we observed significant differences for two options (for the tan color: odds ratio $=2.33,95 \%$ CI $[0.99,5.51]$, Cohen's $h=0.27,95 \%$ CI $[-0.02,0.56]$; for the red color: odds ratio $=3.11,95 \%$ CI $[1.56,6.20]$, Cohen's $h=0.46,95 \%$ CI $[0.17,0.74])$. Comparing the status quo framing with the neutral framing, all differences were non-significant, with the option of tan color exhibiting the largest effect size (odds ratio $=2.00,95 \% \mathrm{CI}[0.68$, 5.89], Cohen's $h=0.23,95 \%$ CI [-0.12, 0.58]). Overall, our data provided limited support for the status quo bias in Scenario 2. 
Table 3. Status quo vs. non-status quo ( $2^{\text {nd }}$ phase $)$

\begin{tabular}{|c|c|c|c|c|c|c|c|}
\hline \multirow[b]{2}{*}{ Options } & \multicolumn{3}{|c|}{ Choice rates } & \multicolumn{4}{|c|}{ Status quo vs. non-status quo } \\
\hline & SQ & $\mathbf{N}$ & NSQ & $\chi^{2}$ & $p$ & $\begin{array}{l}\text { Odd ratio } \\
(95 \% \text { CI })\end{array}$ & $\begin{array}{l}\text { Cohen's } h \\
\text { (95\% CI) }\end{array}$ \\
\hline \multicolumn{8}{|c|}{ Scenario 1: budget allocation ratios } \\
\hline $70 \mathrm{~A} 30 \mathrm{H}$ & $18 / 63(.29)$ & $8 / 65(.12)$ & 20/188 (.11) & 11.81 & .001 & $3.36[1.64,6.88]$ & $0.46[0.18,0.75]$ \\
\hline 30A70H & $35 / 62(.56)$ & $11 / 65(.17)$ & $38 / 189(.20)$ & 29.90 & $<.001$ & $5.15[2.78,9.53]$ & $0.77[0.48,1.06]$ \\
\hline $60 \mathrm{~A} 40 \mathrm{H}$ & $25 / 63(.40)$ & $14 / 65(.22)$ & 36/188 (.19) & 10.81 & .001 & $2.78[1.49,5.17]$ & $0.46[0.17,0.74]$ \\
\hline $50 \mathrm{~A} 50 \mathrm{H}$ & $40 / 63(.63)$ & $32 / 65(.49)$ & $36 / 125(.29)$ & 20.93 & $<.001$ & $4.30[2.26,8.18]$ & $0.71[0.41,1.01]$ \\
\hline \multicolumn{8}{|c|}{ Scenario 2: wagon colors } \\
\hline Red & $19 / 61(.31)$ & $15 / 66(.23)$ & 24/189 (.13) & 11.02 & .001 & $3.11[1.56,6.20]$ & $0.46[0.17,0.74]$ \\
\hline Silver Blue & $33 / 66(.50)$ & $31 / 66(.47)$ & $99 / 184(.54)$ & 0.28 & .595 & $0.86[0.49,1.51]$ & $-0.08[-0.36,0.21]$ \\
\hline Tan & $10 / 60(.17)$ & $6 / 66(.09)$ & $15 / 190(.08)$ & 3.90 & .048 & $2.33[0.99,5.51]$ & $0.27[-0.02,0.56]$ \\
\hline White & $13 / 63(.21)$ & $14 / 66(.21)$ & $37 / 187(.20)$ & 0.02 & .884 & $1.05[0.52,2.14]$ & $0.02[-0.26,0.31]$ \\
\hline \multicolumn{8}{|c|}{ Scenario 3: investment portfolios } \\
\hline Mod. Risk & $22 / 64(.34)$ & $15 / 63(.24)$ & $43 / 189(.23)$ & 3.38 & .066 & $1.78[0.96,3.30]$ & $0.26[-0.02,0.54]$ \\
\hline High Risk & $9 / 64(.14)$ & $7 / 63(.11)$ & $17 / 189(.09)$ & 1.33 & .249 & $1.66[0.70,3.92]$ & $0.16[-0.12,0.44]$ \\
\hline Treasury & $36 / 62(.58)$ & $27 / 63(.43)$ & 79/191 (.41) & 5.27 & .022 & $1.96[1.10,3.51]$ & $0.34[0.05,0.62]$ \\
\hline Municipal & $21 / 63(.33)$ & $14 / 63(.22)$ & $26 / 190(.14)$ & 12.08 & .001 & $3.15[1.62,6.15]$ & $0.47[0.19,0.76]$ \\
\hline \multicolumn{8}{|c|}{ Scenario 4: college jobs } \\
\hline College A & $16 / 63(.25)$ & $10 / 62(.16)$ & 16/191 (.08) & 12.46 & $<.001$ & $3.72[1.73,7.99]$ & $0.47[0.18,0.75]$ \\
\hline College B & $33 / 65(.51)$ & $23 / 62(.37)$ & $43 / 189$ (.23) & 18.11 & $<.001$ & $3.50[1.93,6.34]$ & $0.59[0.31,0.87]$ \\
\hline College C & $36 / 63(.57)$ & $18 / 62(.29)$ & $41 / 191(.21)$ & 28.54 & $<.001$ & $4.88[2.66,8.95]$ & $0.75[0.47,1.04]$ \\
\hline College D & $23 / 63(.37)$ & $11 / 62(.18)$ & 46/191 (.24) & 3.70 & .055 & $1.81[0.98,3.34]$ & $0.27[-0.01,0.56]$ \\
\hline
\end{tabular}

Note. $\mathrm{SQ}=$ status quo, $\mathrm{N}=$ neutral, $\mathrm{NSQ}=$ non-status quo.

Table 4. Status quo vs. neutral ( $2^{\text {nd }}$ phase)

\begin{tabular}{|c|c|c|c|c|c|c|c|}
\hline \multirow[b]{2}{*}{ Options } & \multicolumn{3}{|c|}{ Choice rates } & \multicolumn{4}{|c|}{ Status quo vs. neutral } \\
\hline & SQ & $\mathbf{N}$ & NSQ & $\chi^{2}$ & $p$ & $\begin{array}{l}\text { Odd ratio } \\
(95 \% \text { CI) }\end{array}$ & $\begin{array}{l}\text { Cohen's } h \\
\text { (95\% CI) }\end{array}$ \\
\hline \multicolumn{8}{|c|}{ Scenario 1: budget allocation ratios } \\
\hline $70 \mathrm{~A} 30 \mathrm{H}$ & $18 / 63(.29)$ & $8 / 65(.12)$ & $20 / 188(.11)$ & 5.23 & .022 & $2.85[1.14,7.15]$ & $0.41[0.06,0.76]$ \\
\hline $30 \mathrm{~A} 70 \mathrm{H}$ & $35 / 62(.56)$ & $11 / 65(.17)$ & $38 / 189(.20)$ & 21.46 & $<.001$ & $6.36[2.80,14.45]$ & $0.85[0.50,1.20]$ \\
\hline $60 \mathrm{~A} 40 \mathrm{H}$ & $25 / 63(.40)$ & $14 / 65(.22)$ & $36 / 188(.19)$ & 4.97 & .026 & $2.40[1.10,5.21]$ & $0.40[0.05,0.74]$ \\
\hline $50 \mathrm{~A} 50 \mathrm{H}$ & $40 / 63(.63)$ & $32 / 65(.49)$ & $36 / 125(.29)$ & 2.64 & 104 & $1.79[0.88,3.64]$ & $0.29[-0.06,0.64]$ \\
\hline \multicolumn{8}{|c|}{ Scenario 2: wagon colors } \\
\hline Red & $19 / 61(.31)$ & $15 / 66(.23)$ & $24 / 189(.13)$ & 1.15 & 284 & $1.54[0.70,3.39]$ & $0.19[-0.16,0.54]$ \\
\hline Silver Blue & $33 / 66(.50)$ & $31 / 66(.47)$ & $99 / 184(.54)$ & 0.12 & .728 & $1.13[0.57,2.24]$ & $0.06[-0.28,0.40]$ \\
\hline Tan & $10 / 60(.17)$ & $6 / 66(.09)$ & $15 / 190(.08)$ & 1.63 & 202 & $2.00[0.68,5.89]$ & $0.23[-0.12,0.58]$ \\
\hline White & $13 / 63(.21)$ & $14 / 66(.21)$ & $37 / 187(.20)$ & 0.01 & .936 & $0.97[0.41,2.26]$ & $-0.01[-0.36,0.33]$ \\
\hline \multicolumn{8}{|c|}{ Scenario 3: investment portfolios } \\
\hline Mod. Risk & $22 / 64(.34)$ & $15 / 63(.24)$ & $43 / 189(.23)$ & 1.72 & 190 & $1.68[0.77,3.64]$ & $0.23[-0.11,0.58]$ \\
\hline High Risk & $9 / 64(.14)$ & $7 / 63(.11)$ & $17 / 189(.09)$ & 0.25 & .616 & $1.31[0.46,3.76]$ & $0.09[-0.26,0.44]$ \\
\hline Treasury & $36 / 62(.58)$ & $27 / 63(.43)$ & 79/191 (.41) & 2.89 & .089 & $1.85[0.91,3.75]$ & $0.31[-0.05,0.66]$ \\
\hline Municipal & $21 / 63(.33)$ & $14 / 63(.22)$ & $26 / 190(.14)$ & 1.94 & .164 & $1.75[0.79,3.86]$ & $0.25[-0.10,0.60]$ \\
\hline \multicolumn{8}{|c|}{ Scenario 4: college jobs } \\
\hline College A & $16 / 63(.25)$ & $10 / 62(.16)$ & $16 / 191(.08)$ & 1.63 & .202 & $1.77[0.73,4.28]$ & $0.23[-0.12,0.58]$ \\
\hline College B & $33 / 65(.51)$ & $23 / 62(.37)$ & $43 / 189(.23)$ & 2.41 & .121 & $1.75[0.86,3.55]$ & $0.28[-0.07,0.62]$ \\
\hline College C & $36 / 63(.57)$ & $18 / 62(.29)$ & $41 / 191(.21)$ & 10.06 & .002 & $3.26[1.55,6.84]$ & $0.58[0.23,0.93]$ \\
\hline College D & $23 / 63(.37)$ & $11 / 62(.18)$ & 46/191 (.24) & 5.56 & .018 & $2.67[1.16,6.11]$ & $0.43[0.08,0.78]$ \\
\hline
\end{tabular}




\section{Comparing replication to original findings}

A comparison between the original findings (Table $2 \mathrm{~S}$ and $3 \mathrm{~S}$ in the supplementary; Samuelson \& Zeckhauser, 1988, p. 17) and our replication findings suggests that our replication of the status quo bias in Scenario 1, 3, and 4 can be considered successful. Based on LeBel et al.'s (2019) criteria for evaluating replication results (see Table 5 and 6, and Figure $1 \mathrm{~S}$ in the supplementary), our replication effects in these scenarios were either signals (i.e., significant results) in the expected direction or non-signals that were consistent with the original effects (i.e., the CIs covered the original effects). The replication effect sizes were in general comparable with (Scenario 1 and 3), or larger than (Scenario 4), the original effect sizes. A major discrepancy, however, was found in Scenario 2. Whereas the target study found a significant status quo bias for all options in this scenario (lowest Cohen's $h=0.45$ in the status quo vs. non-status quo comparison), our data revealed no consistently significant status quo bias (status quo vs. nonstatus quo) for any option across the two phases of replications. The largest effect size was Cohen's $h=0.46$ (for the red option in the second phase).

The comparisons between the status quo framing and the neutral framing did not reveal consistent significant differences for any of the scenarios in the original study. Nonetheless, our replication data revealed consistent significant differences for Scenario 1 options (except for the " $30 \mathrm{~A} 70 \mathrm{H}$ " option in the first phase and the "50A50H" option in the second phase). Meanwhile, in line with the original results, we observed a general pattern across Scenarios 1, 3, and 4 that choice rates of options under the status quo framing were higher than under the neutral framing. Scenario 2 results, however, had the largest discrepancy when compared to the original results. The original study observed two significant differences when the status quo framing was compared with the neutral framing, whereas in our replications, only the white color option in the 
first-phase replication had a significant difference in the status quo vs. non-status quo comparison. Moreover, we had three comparisons that yielded effects in the opposite direction (red and silver blue in the first phase and white in the second phase). Overall, our replication findings deviated the most from the original in Scenario 2. 
Table 5. Comparing the replication findings with the original (status quo vs. non-status quo)

\begin{tabular}{|c|c|c|c|}
\hline Option & Original effect size & Replication effect size & Interpretation \\
\hline \multicolumn{4}{|c|}{ First-phase replication } \\
\hline \multicolumn{4}{|l|}{ Scenario 1} \\
\hline $70 \mathrm{~A} 30 \mathrm{H}$ & $0.78[0.42,1.14]$ & $0.62[0.34,0.91]$ & Signal - consistent \\
\hline $30 \mathrm{~A} 70 \mathrm{H}$ & $0.54[0.10,0.99]$ & $0.55[0.25,0.84]$ & Signal - consistent \\
\hline $60 \mathrm{~A} 40 \mathrm{H}$ & $0.79[0.30,1.28]$ & $0.61[0.32,0.89]$ & Signal - consistent \\
\hline $50 \mathrm{~A} 50 \mathrm{H}$ & $0.18[-0.20,0.57]$ & $0.44[0.16,0.73]$ & Signal - consistent \\
\hline \multicolumn{4}{|c|}{ Scenario 2} \\
\hline Red & $0.84[0.51,1.18]$ & $-0.03[-0.32,0.26]$ & No signal - inconsistent \\
\hline Silver Blue & $0.56[0.21,0.90]$ & $-0.03[-0.32,0.25]$ & No signal - inconsistent \\
\hline Tan & $0.45[0.09,0.81]$ & $-0.02[-0.31,0.27]$ & No signal - inconsistent \\
\hline White & $0.51[0.19,0.83]$ & $0.23[-0.06,0.51]$ & No signal - consistent \\
\hline \multicolumn{4}{|c|}{ Second-phase replication } \\
\hline \multicolumn{4}{|l|}{ Scenario 1} \\
\hline $70 \mathrm{~A} 30 \mathrm{H}$ & $0.78[0.42,1.14]$ & $0.46[0.18,0.75]$ & Signal - inconsistent, smaller \\
\hline $30 \mathrm{~A} 70 \mathrm{H}$ & $0.54[0.10,0.99]$ & $0.77[0.48,1.06]$ & Signal - consistent \\
\hline $60 \mathrm{~A} 40 \mathrm{H}$ & $0.79[0.30,1.28]$ & $0.46[0.17,0.74]$ & Signal - inconsistent, smaller \\
\hline $50 \mathrm{~A} 50 \mathrm{H}$ & $0.18[-0.20,0.57]$ & $0.71[0.41,1.01]$ & Signal - inconsistent \\
\hline \multicolumn{4}{|c|}{ Scenario 2} \\
\hline Red & $0.84[0.51,1.18]$ & $0.46[0.17,0.74]$ & Signal - inconsistent, smaller \\
\hline Silver Blue & $0.56[0.21,0.90]$ & $-0.08[-0.36,0.21]$ & No signal - inconsistent \\
\hline Tan & $0.45[0.09,0.81]$ & $0.27[-0.02,0.56]$ & No signal - consistent \\
\hline White & $0.51[0.19,0.83]$ & $0.02[-0.26,0.31]$ & No signal - inconsistent \\
\hline \multicolumn{4}{|c|}{ Scenario 3} \\
\hline Mod. Risk & $0.21[-0.30,0.71]$ & $0.26[-0.02,0.54]$ & No signal - consistent \\
\hline High Risk & $0.16[-0.26,0.58]$ & $0.16[-0.12,0.44]$ & No signal - consistent \\
\hline Treasury & $0.29[-0.09,0.67]$ & $0.34[0.05,0.62]$ & Signal - consistent \\
\hline Municipal & $0.57[0.08,1.07]$ & $0.47[0.19,0.76]$ & Signal - consistent \\
\hline \multicolumn{4}{|l|}{ Scenario 4} \\
\hline College A & $0.17[-0.17,0.51]$ & $0.47[0.18,0.75]$ & Signal - inconsistent, larger \\
\hline College B & $0.12[-0.31,0.56]$ & $0.59[0.31,0.87]$ & Signal - inconsistent, larger \\
\hline College C & $0.74[0.26,1.21]$ & $0.75[0.47,1.04]$ & Signal - consistent \\
\hline College D & $0.52[0.11,0.93]$ & $0.27[-0.01,0.56]$ & No signal - consistent \\
\hline
\end{tabular}

Note. Effect sizes in Cohen's $h$. Interpretation based on LeBel et al. $(2019$, p. 4). 
Table 6. Comparing the replication findings with the original (status quo vs. neutral)

\begin{tabular}{|c|c|c|c|}
\hline Option & Original effect size & Replication effect size & Interpretation \\
\hline \multicolumn{4}{|c|}{ First-phase replication } \\
\hline \multicolumn{4}{|l|}{ Scenario 1} \\
\hline $70 \mathrm{~A} 30 \mathrm{H}$ & $0.74[0.27,1.21]$ & $0.57[0.22,0.92]$ & Signal - consistent \\
\hline $30 \mathrm{~A} 70 \mathrm{H}$ & $0.30[-0.25,0.84]$ & $0.19[-0.16,0.54]$ & No signal - consistent \\
\hline $60 \mathrm{~A} 40 \mathrm{H}$ & $0.34[-0.24,0.92]$ & $0.52[0.17,0.87]$ & Signal - consistent \\
\hline $50 \mathrm{~A} 50 \mathrm{H}$ & $0.25[-0.24,0.74]$ & $0.38[0.03,0.73]$ & Signal - consistent \\
\hline \multicolumn{4}{|c|}{ Scenario 2} \\
\hline Red & $0.67[0.17,1.17]$ & $-0.25[-0.60,0.10]$ & No signal - inconsistent \\
\hline Silver Blue & $0.51[0.00,1.02]$ & $-0.05[-0.40,0.30]$ & No signal - inconsistent \\
\hline Tan & $0.14[-0.37,0.66]$ & $0.00[-0.35,0.35]$ & No signal - consistent \\
\hline White & $0.25[-0.24,0.74]$ & $0.41[0.06,0.76]$ & Signal - consistent \\
\hline \multicolumn{4}{|c|}{ Second-phase replication } \\
\hline \multicolumn{4}{|l|}{ Scenario 1} \\
\hline $70 \mathrm{~A} 30 \mathrm{H}$ & $0.74[0.27,1.21]$ & $0.41[0.06,0.76]$ & Signal - consistent \\
\hline $30 \mathrm{~A} 70 \mathrm{H}$ & $0.30[-0.25,0.84]$ & $0.85[0.50,1.20]$ & Signal - inconsistent, larger \\
\hline $60 \mathrm{~A} 40 \mathrm{H}$ & $0.34[-0.24,0.92]$ & $0.40[0.05,0.74]$ & Signal - consistent \\
\hline $50 \mathrm{~A} 50 \mathrm{H}$ & $0.25[-0.24,0.74]$ & $0.29[-0.06,0.64]$ & No signal - consistent \\
\hline \multicolumn{4}{|c|}{ Scenario 2} \\
\hline Red & $0.67[0.17,1.17]$ & $0.19[-0.16,0.54]$ & No signal - inconsistent \\
\hline Silver Blue & $0.51[0.00,1.02]$ & $0.06[-0.28,0.40]$ & No signal - inconsistent \\
\hline Tan & $0.14[-0.37,0.66]$ & $0.23[-0.12,0.58]$ & No signal - consistent \\
\hline White & $0.25[-0.24,0.74]$ & $-0.01[-0.36,0.33]$ & No signal - consistent \\
\hline \multicolumn{4}{|l|}{ Scenario 3} \\
\hline Mod. Risk & $0.14[-0.45,0.73]$ & $0.23[-0.11,0.58]$ & No signal - consistent \\
\hline High Risk & $0.23[-0.29,0.75]$ & $0.09[-0.26,0.44]$ & No signal - consistent \\
\hline Treasury & $0.26[-0.21,0.73]$ & $0.31[-0.05,0.66]$ & No signal - consistent \\
\hline Municipal & $0.31[-0.27,0.90]$ & $0.25[-0.10,0.60]$ & No signal - consistent \\
\hline \multicolumn{4}{|l|}{ Scenario 4} \\
\hline College A & $0.28[-0.11,0.66]$ & $0.23[-0.12,0.58]$ & No signal - consistent \\
\hline College B & $0.41[-0.08,0.90]$ & $0.28[-0.07,0.62]$ & No signal - consistent \\
\hline College C & $0.26[-0.26,0.79]$ & $0.58[0.23,0.93]$ & Signal - consistent \\
\hline College D & $0.53[0.07,1.00]$ & $0.43[0.08,0.78]$ & Signal - consistent \\
\hline
\end{tabular}

Note. Effect sizes in Cohen's $h$. Interpretation based on LeBel et al. (2019, p. 4). 


\section{Discussion}

We conducted two phases of pre-registered replications of the status quo bias, focusing on four hypothetical decision scenarios from Samuelson and Zeckhauser (1988). Our results were mostly consistent with the original findings. We found support for the status quo bias in three scenarios but weak-to-no support for the bias in the remaining scenario (i.e., Scenario 2). In addition, our results also suggest that the magnitude of the bias varied depending on the decisionmaking context. We observed the strongest bias in Scenario 1, followed by 4 and 3 . In what follows, we discuss possible factors that might have caused the varying magnitudes across scenarios.

\section{Factors affecting status quo bias}

The perceived cost of a change and uncertainties associated with the outcomes of changes could affect the status quo bias (Anderson, 2003; Iyengar \& Lepper, 2000). In Scenario 2, which was about choosing the color for one's preordered wagon, the perceived cost of a change should be close to zero even if decision-makers seriously take that into consideration; all it takes for a change is a word to the wagon dealer. In addition, there is little uncertainty associated with such a change. Based on the description of the scenario, once a person opts for a change, the person is sure to bag the color that he or she prefers. In contrast, for the other scenarios, there was still room for decision-makers to infer transition costs that were not explicitly ruled out in the scenario descriptions. These costs could be material or mental. For example, the status quo version of Scenario 4 asked whether one chooses to remain in the current job or to accept a job offer from other colleges at different locations. For this decision question, participants could have easily inferred the cost of moving and reestablishing personal networks. It is also highly uncertain whether the job that one switches to will be satisfactory, as real-life experience tells us 
that job satisfaction can easily be influenced by numerous unforeseen factors. Scenario 3 could be an example for potential mental costs. Faced with different investment portfolios, those who were less willing to engage in effortful thinking (i.e., calculating the expected gains for each of the options and comparing them) for various reasons (e.g., they may think they lack the expertise) would be prone to stick with the status quo. The need to calculate the expected gains also implies risks and uncertainty. Overall, Scenario 2 stood in sharp contrast with the other three scenarios with respect to the perceived cost of changes and uncertainties associated with the outcomes, which might have resulted in our failure of replicating the status quo bias in the scenario.

It is reasonable to argue that Scenario 1, which was about an impactful public financial decision, involved more concerns (and hence more room for inferred cost of a change) and a higher level of uncertainty than other scenarios did. As the consequence, participants demonstrated the strongest and most robust status quo bias in this scenario. That it was related to a public financial decision might also have implied that the status quo choice has passed the scrutiny of many others', leading to little perceived need for a change and hence a larger status quo bias (Simon, 1956). Nonetheless, our measures and data were not sufficient to test these claims.

Existence and longevity biases, which were said to underlie our status quo preference (Eidelman \& Crandall, 2012, 2014), could also explain the varying sizes of the status quo bias across the scenarios. It was explicitly stated in the description of Scenario 2 that the status quo color option was set two days ago ("Two days ago, the dealer called saying that a red wagon was available."). This relatively shorter period of existence (as compared with the status quo options in the other scenarios, though how long those options have existed was not specified) could have been the reason why the status quo bias was trivial in Scenario 2. 
It is plausible to argue that participants were not so motivated to maintain the status quo in Scenario 2 given how the scenario was constructed. The status quo option, i.e., the color option that the wagon dealer said to be the only one available, was more a compelled rather than an autonomous choice. Forgoing the choice and switching to an alternative, therefore, would produce little cognitive dissonance, which was thought to be a reason why the status quo is maintained and defended (Festinger, 1962; Jost et al., 2004; Kay et al., 2009; Eidelman \& Crandall, 2014). Additionally, in Scenario 2, the decision-maker was yet to own the wagon when he or she was to make the decision whether to switch the color, loss aversion should have no role in leading to the status quo bias in that scenario.

Per the self-perception account of the status quo bias, people exhibit stronger bias for the status quo when they perceive it to be reflective of their own preferences and needs (Bem, 1972; Samuelson \& Zeckhauser, 1988; Eidelman \& Crandall, 2014). And the need for consistency drives us to maintain the status quo. From this perspective, there could be two reasons for the weak-to-no status quo preference in Scenario 2. First, as said above, the status quo color option in Scenario 2 was more like a compelled choice. Recognizing this, participants would not think that they made the initial decision based on their preferences ("I was only given that option by the wagon dealer. I had no choice.”). Consequently, there was no reason or motivation for them to stick with the status quo option if they found the alternatives more attractive. Second, preferences for colors are arguably more accessible than preferences for investment portfolios (Scenario 3), job offers (Scenario 4), and safety research programs (Scenario 1). Most people have clearer preferences for colors than for the other things. When prompted, they can tell color preferences more quickly, firmly, and with more subjective reasons (e.g., "I like this color just because of personal aesthetics"). Strong prior preferences are a major hinderance for context effects on 
decision-making because they lead people to ignore contextual factors and make decisions based on their own likes and dislikes (Huber et al., 2014). Our results for Scenario 2, therefore, were consistent with the claim that people exhibit no or weaker status quo bias if some alternative appears substantially more appealing than the competitors.

\section{Limitations and future directions}

We were limited by our inability to experimentally control or manipulate the factors that we discussed above, since our aimed primarily at direct replications. Still, we did not attempt to replicate the original experiment in full, leaving out some original scenarios and using only the four-option versions. To what extent the original results for the other scenarios and other types of decision questions (e.g., Question 7 and 8 that provided a continuum of options; Part Two that elicited sequential decisions from participants) can be replicated, and whether the claim that the more options there are, the stronger the status quo bias is remains supported across scenarios (see, e.g., Redelmeier \& Shafir, 1995), are questions worth addressing in future studies. To be precise, what we attempted to replicate was the effect of status quo framing, since our experiments did not involve participants' actual previous choices. Therefore, more evidence is needed if our findings are to be generalized to situations where actual previous choices serve as the status quo.

Direct replications of the classic and influential findings of Samuelson and Zeckhauser (1988) served to assess whether their results were reliable and robust across time, samples, and experimental settings. Examining how different factors moderate the status quo bias, however, was beyond the scope of our investigation. Future research on the status quo bias can measure or control for potential moderators and explore the circumstances that influence its manifestation and magnitude. 
The value of direct replications, particularly those on what are perceived to be old and well-established phenomena, is often questioned. However, as the whole field of psychology is shifting away from identification of effects to provision of accurate effect size estimations (Cumming, 2014), we believe more direct replications should be conducted, especially those on classic effects. Only by aggregating, or meta-analyzing, enough similar studies can we obtain an accurate estimation of the size of a particular effect and have an informed expectation on the outcome when the effect is to be applied in the real world. The discrepancy that we revealed between the original results and our findings does not invalidate the overall claim about the existence of the status quo bias; nonetheless, the we recommend caution regarding the claim that the bias is pervasive in decision-making scenarios (e.g., Samuelson \& Zeckhauser, 1988, p. 41). Our findings also highlight the need for more direct replications (ideally in the form of multi-lab collaborative Registered Reports; Klein et al., 2018; Nosek \& Lakens, 2014) on classic findings, some of which were derived from insufficiently powered experiments using unrepresentative college student samples. Subjecting evidence obtained in original studies and in replications to meta-analyses, we will be able to gain more comprehensive and precise pictures of effects and their boundary conditions. 


\section{References}

Abadie, A., \& Gay, S. (2006). The impact of presumed consent legislation on cadaveric organ donation: A cross-country study. Journal of Health Economics, 25(4), 599-620. https://doi.org/10.1016/j.jhealeco.2006.01.003

Anderson, C. J. (2003). The psychology of doing nothing: Forms of decision avoidance result from reason and emotion. Psychological Bulletin, 129(1), 139-167. https://doi.org/10.1037/0033-2909.129.1.139

Ariely, D., Loewenstein, G., \& Prelec, D. (2003). "Coherent arbitrariness": Stable demand curves without stable preferences. The Quarterly Journal of Economics, 118(1), 73-106. https://doi.org/10.1162/00335530360535153

Atkinson, M. M. (2011). Lindblom's lament: Incrementalism and the persistent pull of the status quo. Policy and Society, 30(1), 9-18. https://doi.org/10.1016/j.polsoc.2010.12.002

Baron, J., \& Ritov, I. (1994). Reference points and omission bias. Organizational Behavior and Human Decision Processes, 59(3), 475-498. https://doi.org/10.1006/obhd.1994.1070

Bem, D. J. (1972). Self-perception theory. In L. Berkowitz (Ed.), Advances in Experimental Social Psychology (Vol. 6, pp. 1-62). Academic Press. https://www.sciencedirect.com/science/article/pii/S0065260108600246

Bergman, O., Ellingsen, T., Johannesson, M., \& Svensson, C. (2010). Anchoring and cognitive ability. Economics Letters, 107(1), 66-68. https://doi.org/10.1016/j.econlet.2009.12.028

Brandt, M. J., IJzerman, H., Dijksterhuis, A., Farach, F. J., Geller, J., Giner-Sorolla, R., Grange, J. A., Perugini, M., Spies, J. R., \& van 't Veer, A. (2014). The Replication Recipe: What makes for a convincing replication? Journal of Experimental Social Psychology, 50, 217224. https://doi.org/10.1016/j.jesp.2013.10.005 
Brehm, J. W. (1956). Postdecision changes in the desirability of alternatives. The Journal of Abnormal and Social Psychology, 52(3), 384-389. https://doi.org/10.1037/h0041006

Cohen, J. (1988). Statistical power analysis for the behavioral sciences (2nd ed.). L. Erlbaum Associates.

Connolly, T., \& Zeelenberg, M. (2002). Regret in decision making. Current Directions in Psychological Science, 11(6), 212-216. https://doi.org/10.1111/1467-8721.00203

Cox, G. W., \& Morgenstern, S. (1993). The increasing advantage of incumbency in the US states. Legislative Studies Quarterly, 18(4), 495-514. https://doi.org/10.2307/439852

Cumming, G. (2014). The new statistics: Why and how. Psychological Science, 25(1), 7-29. https://doi.org/10.1177/0956797613504966

Dhar, R. (1996). The effect of decision strategy on deciding to defer choice. Journal of Behavioral Decision Making, 9(4), 265-281. https://doi.org/10.1002/(SICI)10990771(199612)9:4<265::AID-BDM231>3.0.CO;2-4

Dupont, D. Y., \& Lee, G. S. (2002). The endowment effect, status quo bias and loss aversion: Rational alternative explanation. Journal of Risk and Uncertainty, 25, 87-101. https://doi.org/10.1023/A:1016371414952

Eidelman, S., \& Crandall, C. S. (2012). Bias in favor of the status quo. Social and Personality Psychology Compass, 6(3), 270-281. https://doi.org/10.1111/j.1751-9004.2012.00427.x

Eidelman, S., \& Crandall, C. S. (2014). The intuitive traditionalist: How biases for existence and longevity promote the status quo. In Advances in Experimental Social Psychology (Vol. 50, pp. 53-104). Elsevier. https://doi.org/10.1016/B978-0-12-800284-1.00002-3

Eidelman, S., Crandall, C. S., \& Pattershall, J. (2009). The existence bias. Journal of Personality and Social Psychology, 97(5), 765-775. https://doi.org/10.1037/a0017058 
Eidelman, S., Pattershall, J., \& Crandall, C. S. (2010). Longer is better. Journal of Experimental Social Psychology, 46(6), 993-998. https://doi.org/10.1016/j.jesp.2010.07.008

Erikson, R. S. (1971). The advantage of incumbency in congressional elections. Polity, 3(3), 395-405. https://doi.org/10.2307/3234117

Eyster, E. (2002). Rationalizing the past: A taste for consistency. Nuffield College Mimeograph. http://www.lse.ac.uk/economics/Assets/Documents/personal-pages/erikeyster/rationalising-the-past-a-taste-for-consistency.pdf

Feldman, G., Kutscher, L., \& Yay, T. (2020). Omission and commission in judgment and decision making: Understanding and linking action-inaction effects using the concept of normality. Social and Personality Psychology Compass, 14(8), e12557. https://doi.org/10.1111/spc3.12557

Festinger, L. (1962). A theory of cognitive dissonance (Vol. 2). Stanford University Press. Festinger, L., \& Carlsmith, J. M. (1959). Cognitive consequences of forced compliance. Journal of Abnormal and Social Psychology, 58(2), 203-210. https://doi.org/10.1037/h0041593

Fudenberg, D., Levine, D. K., \& Maniadis, Z. (2012). On the robustness of anchoring effects in WTP and WTA experiments. American Economic Journal: Microeconomics, 4(2), 131145. https://doi.org/10.1257/mic.4.2.131

Gelman, A. (2019). Don't calculate post-hoc power using observed estimate of effect size. Annals of Surgery, 269(1), e9. https://doi.org/10.1097/SLA.0000000000002908

Gigerenzer, G., \& Selten, R. (2002). Bounded rationality: The adaptive toolbox. MIT Press. Gunaydin, G., Selcuk, E., Yilmaz, C., \& Hazan, C. (2018). I have, therefore I love: Status quo preference in mate choice. Personality and Social Psychology Bulletin, 44(4), 589-600. https://doi.org/10.1177/0146167217746339 
Hartman, R. S., Doane, M. J., \& Woo, C.-K. (1991). Consumer rationality and the status quo. The Quarterly Journal of Economics, 106(1), 141-162. https://doi.org/10.2307/2937910

Huber, J., Payne, J. W., \& Puto, C. P. (2014). Let's be honest about the attraction effect. Journal of Marketing Research, 51(4), 520-525. https://doi.org/10.1509/jmr.14.0208

Inman, J. J., \& Zeelenberg, M. (2002). Regret in repeat purchase versus switching decisions: The attenuating role of decision justifiability. Journal of Consumer Research, 29(1), 116-128. https://doi.org/10.1086/339925

Iyengar, S. S., \& Lepper, M. R. (2000). When choice is demotivating: Can one desire too much of a good thing? Journal of Personality and Social Psychology, 79(6), 995-1006. https://doi.org/10.1037/0022-3514.79.6.995

Johnson, E. J., \& Goldstein, D. (2003). Do defaults save lives? Science, 302(5649), 1338-1339. https://doi.org/10.1126/science.1091721

Johnson, E. J., Hershey, J., Meszaros, J., \& Kunreuther, H. (1993). Framing, probability distortions, and insurance decisions. Journal of Risk and Uncertainty, 7, 35-51. https://doi.org/10.1007/BF01065313

Jost, J. T., Banaji, M. R., \& Nosek, B. A. (2004). A decade of system justification theory: Accumulated evidence of conscious and unconscious bolstering of the status quo. Political Psychology, 25(6), 881-919. https://doi.org/10.1111/j.1467-9221.2004.00402.x

Kahneman, D., Knetsch, J. L., \& Thaler, R. H. (1991). Anomalies: The endowment effect, loss aversion, and status quo bias. Journal of Economic Perspectives, 5(1), 193-206. https://doi.org/10.1257/jep.5.1.193

Kay, A. C., Gaucher, D., Peach, J. M., Laurin, K., Friesen, J., Zanna, M. P., \& Spencer, S. J. (2009). Inequality, discrimination, and the power of the status quo: Direct evidence for a 
motivation to see the way things are as the way they should be. Journal of Personality and Social Psychology, 97(3), 421-434. https://doi.org/10.1037/a0015997

Klein, R. A., Vianello, M., Hasselman, F., Adams, B. G., Adams, R. B., Alper, S., Aveyard, M., Axt, J. R., Babalola, M. T., Bahník, Š., Batra, R., Berkics, M., Bernstein, M. J., Berry, D. R., Bialobrzeska, O., Binan, E. D., Bocian, K., Brandt, M. J., Busching, R., ... Nosek, B. A. (2018). Many Labs 2: Investigating variation in replicability across samples and settings. Advances in Methods and Practices in Psychological Science, 1(4), 443-490. https://doi.org/10.1177/2515245918810225

Kleiser, S. B., \& Wagner, J. A. (1999). Understanding the pioneering advantage from the decision maker's perspective: The case of product involvement and the status quo bias. NA - Advances in Consumer Research, 26, 593-597.

Kuhn, T. S. (2012). The structure of scientific revolutions. University of Chicago Press.

LeBel, E. P., McCarthy, R. J., Earp, B. D., Elson, M., \& Vanpaemel, W. (2018). A unified framework to quantify the credibility of scientific findings. Advances in Methods and Practices in Psychological Science, 1(3), 389-402. https://doi.org/10.1177/2515245918787489

LeBel, E. P., Vanpaemel, W., Cheung, I., \& Campbell, L. (2019). A brief guide to evaluate replications. Meta-Psychology, 3. https://doi.org/10.15626/MP.2018.843

Lieberman, M. B., \& Montgomery, D. B. (1988). First-mover advantages. Strategic Management Journal, 9(S1), 41-58. https://doi.org/10.1002/smj.4250090706

Lieder, F., \& Griffiths, T. L. (2020). Resource-rational analysis: Understanding human cognition as the optimal use of limited computational resources. Behavioral and Brain Sciences, 43, E1. https://doi.org/10.1017/S0140525X1900061X 
Loewenstein, G. F., Weber, E. U., Hsee, C. K., \& Welch, N. (2001). Risk as feelings.

Psychological Bulletin, 127(2), 267-286. https://doi.org/10.1037/0033-2909.127.2.267

Luce, M. F. (1998). Choosing to avoid: Coping with negatively emotion-laden consumer decisions. Journal of Consumer Research, 24(4), 409-433. https://doi.org/10.1086/209518

Luce, M. F., Bettman, J. R., \& Payne, J. W. (1997). Choice processing in emotionally difficult decisions. Journal of Experimental Psychology: Learning, Memory, and Cognition, 23(2), 384-405. https://doi.org/10.1037/0278-7393.23.2.384

Maniadis, Z., Tufano, F., \& List, J. A. (2014). One swallow doesn’t make a summer: New evidence on anchoring effects. American Economic Review, 104(1), 277-90. https://doi.org/10.1257/aer.104.1.277

Masatlioglu, Y., \& Ok, E. A. (2005). Rational choice with status quo bias. Journal of Economic Theory, 121(1), 1-29. https://doi.org/10.1016/j.jet.2004.03.007

Montpetit, É., \& Lachapelle, E. (2017). New environmental technology uptake and bias toward the status quo: The case of phytoremediation. Environmental Technology \& Innovation, 7, 102-109. https://doi.org/10.1016/j.eti.2016.12.008

Moshinsky, A., \& Bar-Hillel, M. (2010). Loss aversion and status quo label bias. Social Cognition, 28(2), 191-204. https://doi.org/10.1521/soco.2010.28.2.191

Mrkva, K., Johnson, E. J., Gächter, S., \& Herrmann, A. (2020). Moderating loss aversion: Loss aversion has moderators, but reports of its death are greatly exaggerated. Journal of Consumer Psychology, 30(3), 407-428. https://doi.org/10.1002/jcpy.1156

Muthukrishnan, A. V. (1995). Decision ambiguity and incumbent brand advantage. Journal of Consumer Research, 22(1), 98-109. https://doi.org/10.1086/209438 
Nebel, J. M. (2015). Status quo bias, rationality, and conservatism about value. Ethics, 125(2), 449-476. https://doi.org/10.1086/678482

Nosek, B. A., \& Lakens, D. (2014). Registered Reports: A method to increase the credibility of published results. Social Psychology, 45(3), 137-141. https://doi.org/10.1027/18649335/a000192

Open Science Collaboration. (2015). Estimating the reproducibility of psychological science. Science, 349(6251), aac4716. https://doi.org/10.1126/science.aac4716

Redelmeier, D. A., \& Shafir, E. (1995). Medical decision making in situations that offer multiple alternatives. JAMA, 273(4), 302-305. https://doi.org/10.1001/jama.1995.03520280048038

Ritov, I., \& Baron, J. (1992). Status-quo and omission biases. Journal of Risk and Uncertainty, 5(1), 49-61. https://doi.org/10.1007/bf00208786

Samuelson, W., \& Zeckhauser, R. (1988). Status quo bias in decision making. Journal of Risk and Uncertainty, 1(1), 7-59. https://doi.org/10.1007/BF00055564

Schwartz, B., Ben-Haim, Y., \& Dacso, C. (2011). What makes a good decision? Robust satisficing as a normative standard of rational decision making. Journal for the Theory of Social Behaviour, 41(2), 209-227. https://doi.org/10.1111/j.1468-5914.2010.00450.x

Schwartz, B., Ward, A., Monterosso, J., Lyubomirsky, S., White, K., \& Lehman, D. R. (2002). Maximizing versus satisficing: Happiness is a matter of choice. Journal of Personality and Social Psychology, 83(5), 1178-1197. https://doi.org/10.1037//0022-3514.83.5.1178

Schweitzer, M. (1994). Disentangling status quo and omission effects: An experimental analysis. Organizational Behavior and Human Decision Processes, 58(3), 457-476. https://doi.org/10.1006/obhd.1994.1046 
Shevchenko, Y., von Helversen, B., \& Scheibehenne, B. (2014). Change and status quo in decisions with defaults: The effect of incidental emotions depends on the type of default. Judgment and Decision Making, 9(3), 287-296.

Shi, X., Lin, Z., Liu, J., \& Hui, Y. K. (2018). Consumer loyalty toward smartphone brands: The determining roles of deliberate inertia and cognitive lock-in. Information \& Management, 55(7), 866-876. https://doi.org/10.1016/j.im.2018.03.013

Simon, H. A. (1956). Rational choice and the structure of the environment. Psychological Review, 63(2), 129-138. https://doi.org/10.1037/h0042769

Suri, G., Sheppes, G., Schwartz, C., \& Gross, J. J. (2013). Patient inertia and the status quo bias: When an inferior option is preferred. Psychological Science, 24(9), 1763-1769. https://doi.org/10.1177/0956797613479976

Thaler, R. H. (1980). Toward a positive theory of consumer choice. Journal of Economic Behavior \& Organization, 1(1), 39-60. https://doi.org/10.1016/0167-2681(80)90051-7

Tversky, A., \& Kahneman, D. (1974). Judgment under uncertainty: Heuristics and biases. Science, 185(4157), 1124-1131. https://doi.org/10.1126/science.185.4157.1124

Tversky, A., \& Kahneman, D. (1981). The framing of decisions and the psychology of choice. Science, 211(4481), 453-458. https://doi.org/10.1126/science.7455683

Tversky, A., \& Kahneman, D. (1991). Loss aversion in riskless choice: A reference-dependent model. The Quarterly Journal of Economics, 106(4), 1039-1061. https://doi.org/10.2307/2937956

Tversky, A., \& Shafir, E. (1992). Choice under conflict: The dynamics of deferred decision. Psychological Science, 3(6), 358-361. https://doi.org/10.1111/j.14679280.1992.tb00047.x 
Tykocinski, O. E., \& Pittman, T. S. (1998). The consequences of doing nothing: Inaction inertia as avoidance of anticipated counterfactual regret. Journal of Personality and Social Psychology, 75(3), 607-616. https://doi.org/10.1037/0022-3514.75.3.607

Tykocinski, O. E., Pittman, T. S., \& Tuttle, E. E. (1995). Inaction inertia: Foregoing future benefits as a result of an initial failure to act. Journal of Personality and Social Psychology, 68(5), 793-803. https://doi.org/10.1037/0022-3514.68.5.793

van ’t Veer, A. E., \& Giner-Sorolla, R. (2016). Pre-registration in social psychology-A discussion and suggested template. Journal of Experimental Social Psychology, 67, 2-12. https://doi.org/10.1016/j.jesp.2016.03.004

Yen, H. R., \& Chuang, S.-C. (2008). The effect of incidental affect on preference for the status quo. Journal of the Academy of Marketing Science, 36(4), 522-537. https://doi.org/10.1007/s11747-008-0084-2

Zajonc, R. B. (1968). Attitudinal effects of mere exposure. Journal of Personality and Social Psychology, 9(2, Pt. 2), 1-27. https://doi.org/10.1037/h0025848

Zwaan, R. A., Etz, A., Lucas, R. E., \& Donnellan, M. B. (2018). Making replication mainstream. Behavioral and Brain Sciences, 41. https://doi.org/10.1017/S0140525X17001972 


\section{Status quo bias: Replication of Samuelson and Zeckhauser (1988) Supplementary}

Contents

Contributor Roles Taxonomy 2

Open Science Disclosures 2

Study materials 2

Procedure and data disclosures 2

Original Results 3

Power Analysis 4

Post hoc power in the target article

Sensitivity analysis 5

Comparisons and Deviations 6

Sample comparison 6

Results after exclusion

First-phase replication 8

Second-phase replication 8

Replication evaluation 10

Error documentation 12

References 


\section{Contributor Roles Taxonomy}

Authors' respective contributions have been identified in Table 1S based on CRediT (Contributor Roles Taxonomy) (please refer to https://www.casrai.org/credit.html on details and definitions of each of the roles listed below).

Table 1S. Contributions by each author

\begin{tabular}{lllll}
\hline Role & Qinyu Xiao & $\begin{array}{l}\text { Gilad } \\
\text { Feldman }\end{array}$ & $\begin{array}{l}\text { Choi Shan } \\
\text { Lam }\end{array}$ & $\begin{array}{l}\text { Muhrajan } \\
\text { Piara }\end{array}$ \\
\hline Conceptualization & & $\mathrm{X}$ & & $\mathrm{X}$ \\
Pre-registration & & $\mathrm{X}$ & $\mathrm{X}$ & $\mathrm{X}$ \\
Data curation & $\mathrm{X}$ & $\mathrm{X}$ & $\mathrm{X}$ \\
Formal analysis & $\mathrm{X}$ & $\mathrm{X}$ & $\mathrm{X}$ \\
Funding acquisition & & $\mathrm{X}$ & $\mathrm{X}$ & $\mathrm{X}$ \\
Investigation & & $\mathrm{X}$ & \\
Pre-registration peer review / verification & $\mathrm{X}$ & $\mathrm{X}$ & \\
Data analysis peer review / verification & $\mathrm{X}$ & & $\mathrm{X}$ \\
Methodology & & $\mathrm{X}$ & & \\
Project administration & & $\mathrm{X}$ & & \\
Resources & & $\mathrm{X}$ & $\mathrm{X}$ & \\
Software & $\mathrm{X}$ & $\mathrm{X}$ & & \\
Supervision & & $\mathrm{X}$ & \\
Validation & $\mathrm{X}$ & $\mathrm{X}$ & & \\
Visualization & $\mathrm{X}$ & $\mathrm{X}$ & \\
Writing - original draft & $\mathrm{X}$ & & \\
Writing-review and editing & & & \\
\hline
\end{tabular}

Open Science Disclosures

\section{Study materials}

Data, analysis scripts, pre-registrations, and Qualtrics questionnaires have been shared on the Open Science Framework (link: https://osf.io/kh8q3).

\section{Procedure and data disclosures}

Data collection Data collection was completed before analyzing the data.

Conditions reporting All collected conditions have been reported.

Data exclusions $\quad$ Details have been reported in this document.

Variables reporting All variables collected for this study have been reported and included in the provided data. 


\section{Original Results}

Table 2S. Status quo vs. non-status quo

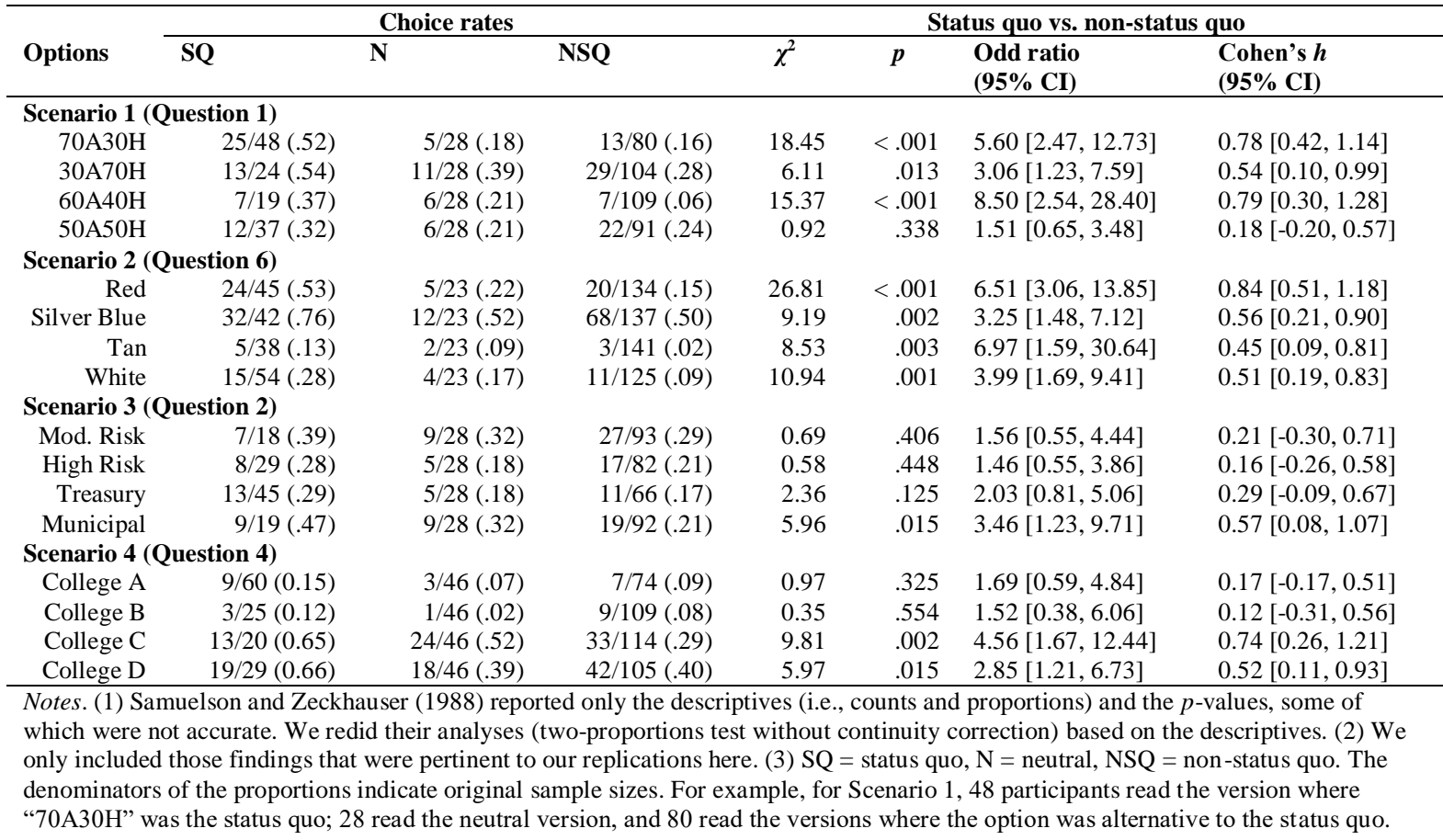

Table 3S. Status quo vs. neutral

\begin{tabular}{|c|c|c|c|c|c|c|c|}
\hline \multirow[b]{2}{*}{ Options } & \multicolumn{3}{|c|}{ Choice rates } & \multicolumn{4}{|c|}{ Status quo vs. neutral } \\
\hline & SQ & $\mathbf{N}$ & NSQ & $\chi^{2}$ & $p$ & $\begin{array}{l}\text { Odd ratio } \\
(95 \% \text { CI })\end{array}$ & $\begin{array}{l}\text { Cohen's } h \\
(95 \% \text { CI })\end{array}$ \\
\hline \multicolumn{8}{|c|}{ Scenario 1 (Question 1) } \\
\hline $70 \mathrm{~A} 30 \mathrm{H}$ & $25 / 48(.52)$ & $5 / 28(.18)$ & $13 / 80(.16)$ & 8.67 & .003 & $5.00[1.63,15.34]$ & $0.74[0.27,1.21]$ \\
\hline $30 \mathrm{~A} 70 \mathrm{H}$ & $13 / 24(.54)$ & $11 / 28(.39)$ & $29 / 104(.28)$ & 1.15 & .283 & $1.83[0.61,5.51]$ & $0.30[-0.25,0.84]$ \\
\hline $60 \mathrm{~A} 40 \mathrm{H}$ & $7 / 19(.37)$ & $6 / 28(.21)$ & $7 / 109(.06)$ & 1.34 & .246 & $2.14[0.58,7.83]$ & $0.34[-0.24,0.92]$ \\
\hline $50 \mathrm{~A} 50 \mathrm{H}$ & $12 / 37(.32)$ & $6 / 28(.21)$ & $22 / 91(.24)$ & 0.96 & .326 & $1.76[0.57,5.48]$ & $0.25[-0.24,0.74]$ \\
\hline \multicolumn{8}{|c|}{ Scenario 2 (Question 6) } \\
\hline Red & $24 / 45(.53)$ & $5 / 23(.22)$ & 20/134 (.15) & 6.21 & .013 & $4.11[1.30,13.01]$ & $0.67[0.17,1.17]$ \\
\hline Silver Blue & $32 / 42(.76)$ & $12 / 23(.52)$ & $68 / 137(.50)$ & 3.92 & .048 & $2.93[0.99,8.67]$ & $0.51[0.00,1.02]$ \\
\hline Tan & $5 / 38(.13)$ & $2 / 23(.09)$ & $3 / 141(.02)$ & 0.28 & .596 & $1.59[0.28,8.96]$ & $0.14[-0.37,0.66]$ \\
\hline White & $15 / 54(.28)$ & $4 / 23(.17)$ & $11 / 125(.09)$ & 0.94 & .333 & $1.83[0.53,6.26]$ & $0.25[-0.24,0.74]$ \\
\hline \multicolumn{8}{|c|}{ Scenario 3 (Question 2) } \\
\hline Mod. Risk & $7 / 18(.39)$ & $9 / 28(.32)$ & $27 / 93(.29)$ & 0.22 & .639 & $1.34[0.39,4.62]$ & $0.14[-0.45,0.73]$ \\
\hline High Risk & $8 / 29(.28)$ & $5 / 28(.18)$ & $17 / 82(.21)$ & 0.77 & .381 & $1.75[0.49,6.20]$ & $0.23[-0.29,0.75]$ \\
\hline Treasury & $13 / 45(.29)$ & $5 / 28(.18)$ & $11 / 66(.17)$ & 1.13 & .288 & $1.87[0.58,5.97]$ & $0.26[-0.21,0.73]$ \\
\hline Municipal & $9 / 19(.47)$ & $9 / 28(.32)$ & $19 / 92(.21)$ & 1.11 & .292 & $1.90[0.57,6.31]$ & $0.31[-0.27,0.90]$ \\
\hline \multicolumn{8}{|c|}{ Scenario 4 (Question 4) } \\
\hline College A & $9 / 60(0.15)$ & $3 / 46(.07)$ & 7/74 (.09) & 1.86 & .172 & $2.53[0.64,9.94]$ & $0.28[-0.11,0.66]$ \\
\hline College B & $3 / 25(0.12)$ & $1 / 46(.02)$ & $9 / 109(.08)$ & 2.94 & .086 & $6.14[0.60,62.44]$ & $0.41[-0.08,0.90]$ \\
\hline College C & $13 / 20(0.65)$ & $24 / 46(.52)$ & $33 / 114(.29)$ & 0.93 & .335 & $1.70[0.57,5.04]$ & $0.26[-0.26,0.79]$ \\
\hline College D & $19 / 29(0.66)$ & $18 / 46(.39)$ & $42 / 105(.40)$ & 4.95 & .026 & $2.96[1.12,7.78]$ & $0.53[0.07,1.00]$ \\
\hline
\end{tabular}




\section{Power Analysis}

We pre-registered our power analyses on OSF (first phase: https://osf.io/c3phs; second phase: https://osf.io/69hzx).

Though we pre-registered a power-analysis, revisiting these calculations following reviewer feedback, we were unable to reconstruct and verify these calculations. We therefore conducted an additional "post hoc" power analysis, which has been documented in the R Notebook that calculated the original effect sizes.

The core hypothesis that we sought to test by running the replications was that an option is chosen more often when it is the status quo than when it is a non-status quo. The original effect sizes for this

hypothesis ranged between 0.12 and 0.84 (see Table $2 \mathrm{~S}$ above). We therefore considered Cohen's $h=0.5$, a medium effect by Cohen's (1988) benchmarks and close to the median of the original effect sizes, as a reasonable target effect size. For a two-sided two-proportions test (with unbalanced sample sizes of $n$ and $3 n$, since the sample in the non-status quo conditions of a particular option should be three times as large as the sample in the status quo condition of that option) to detect this effect size with .95 power, $n$ should not be smaller than 71 .

Since there are five conditions in each scenario (i.e., four SQ conditions for each of the four options and one neutral condition), our power analysis suggests that we would need $5 \times 71=355$ participants. Our actual sample sizes were close to this number. Therefore, we had adequate power in our replications.

\section{Post hoc power in the target article}

We also calculated the achieved power of the original study based on the observed effect sizes (in Cohen's $h$ ). We assumed two-tailed independent-proportions tests and an alpha level of .05 and focused on the SQ vs. NSQ comparisons.

Table 4S. Achieved power of the target article

\begin{tabular}{llllll}
\hline Scenario & Option & $\boldsymbol{n}_{\text {SQ }}$ & $\boldsymbol{n}_{\text {NSQ }}$ & $\begin{array}{l}\text { Effect size } \\
\text { (Cohen's } \boldsymbol{h} \text { ) }\end{array}$ & $\begin{array}{l}\text { Achieved } \\
\text { power }\end{array}$ \\
\hline 1 & $70 \mathrm{~A} 30 \mathrm{H}$ & 48 & 80 & 0.78 & .99 \\
& $30 \mathrm{~A} 70 \mathrm{H}$ & 24 & 104 & 0.54 & .66 \\
& $60 \mathrm{~A} 40 \mathrm{H}$ & 19 & 109 & 0.79 & .89 \\
& 50A50H & 37 & 91 & 0.18 & .15 \\
\hline 2 & Red & 45 & 134 & 0.84 & .99 \\
& Silver Blue & 42 & 137 & 0.56 & .89 \\
& Tan & 38 & 141 & 0.45 & .69 \\
& White & 54 & 125 & 0.51 & .88 \\
\hline 3 & Mod. Risk & 18 & 93 & 0.21 & .13 \\
& High Risk & 29 & 82 & 0.16 & .11 \\
& Treasury & 45 & 66 & 0.29 & .32 \\
\hline 4 & Municipal & 19 & 92 & 0.57 & .16 \\
& College A & 60 & 74 & 0.17 & .08 \\
& College B & 25 & 109 & 0.12 & .86 \\
\hline & College C & 20 & 114 & 0.74 & .57 \\
\hline
\end{tabular}

The average achieved power was .57. Note that the range of achieved power was wide even within scenarios. 


\section{Sensitivity analysis}

We also analyzed the sensitivity of the tests based on the original sample sizes. Again, we assumed twotailed independent-proportions tests and an alpha level of .05. We want to see how sensitive the tests were at the conventionally acceptable power level of .80 .

Table 5S. Sensitivity analyses

\begin{tabular}{lllll}
\hline Scenario & Option & $\boldsymbol{n}_{\mathbf{S Q}}$ & $\boldsymbol{n}_{\mathbf{N S Q}}$ & Sensitivity at .80 power (Cohen's $\boldsymbol{h}$ ) \\
\hline 1 & $70 \mathrm{~A} 30 \mathrm{H}$ & 48 & 80 & 0.51 \\
& $30 \mathrm{~A} 70 \mathrm{H}$ & 24 & 104 & 0.63 \\
& 60A40H & 19 & 109 & 0.70 \\
& 50A50H & 37 & 91 & 0.55 \\
\hline 2 & Red & 45 & 134 & 0.48 \\
& Silver Blue & 42 & 137 & 0.49 \\
& Tan & 38 & 141 & 0.51 \\
& White & 54 & 125 & 0.46 \\
\hline 3 & Mod. Risk & 18 & 93 & 0.72 \\
& High Risk & 29 & 82 & 0.61 \\
& Treasury & 45 & 66 & 0.54 \\
& Municipal & 19 & 92 & 0.71 \\
\hline 4 & College A & 60 & 74 & 0.49 \\
& College B & 25 & 109 & 0.62 \\
& College C & 20 & 114 & 0.68 \\
& College D & 29 & 105 & 0.59 \\
\hline
\end{tabular}

While the average looks acceptable ( .80 power to detect Cohen's $h=0.58$, a medium $(0.5)$ to large $(0.8)$ Cohen's $h$ effect size), the sensitivities varied considerably across options. If we look at the option "Moderate Risk Company A" in Scenario 3, the original sample sizes allowed only Cohen's $h=0.72$ to be detected reliably. 


\section{Comparisons and Deviations}

\section{Sample comparison}

Please refer to the pre-registrations for exclusion criteria.

Table 6S. Comparison between the original and the replication samples

\begin{tabular}{llll}
\hline & $\begin{array}{l}\text { Samuelson \& } \\
\text { Zeckhauser (1988) }\end{array}$ & $\begin{array}{l}\text { American MTurk } \\
\text { workers }\left(1^{\text {st }} \text { phase }\right. \\
\text { replication })\end{array}$ & $\begin{array}{l}\text { American MTurk } \\
\text { workers }\left(2^{\text {nd }} \text { phase }\right. \\
\text { replication })\end{array}$ \\
\hline $\begin{array}{l}\text { Sample size } \\
\text { Geographic origin }\end{array}$ & $\begin{array}{l}\text { See } \text { notes below } \\
\text { The subjects were } \\
\text { students in economic } \\
\text { classes at Boston }\end{array}$ & $\begin{array}{l}311 \\
\text { US American }\end{array}$ & $\begin{array}{l}316 \\
\text { US American }\end{array}$ \\
& $\begin{array}{l}\text { University and Harvard } \\
\text { University. More than }\end{array}$ & & \\
& three-quarters were & & \\
& first-year MBA & & \\
students. & Not available & 147 males, 164 females & 155 males, 161 females \\
Gender & Not available & 35 & 37 \\
Median age (years) & Not available & 38.05 & 38.79 \\
Average age (years) & Not available & $19-77$ & $20-70$ \\
Age range (years) & Paper (administered in- & Computer (online) & Computer (online) \\
Medium (location) & class) & Nominal payment & Nominal payment \\
Compensation & No & 2017 & 2018 \\
Year & Around 1988 & . & \\
\hline
\end{tabular}

Note. A total of 486 students participated in Samuelson and Zeckhauser's (1988) experiment (p. 14). Nonetheless, as there were also two-option and three-option versions of the decision questions in their study, the number of participants that went through the questions used in our replications was smaller. 
Table 7S. Comparison between the original and the replication samples (after exclusion)

\begin{tabular}{|c|c|c|c|}
\hline & $\begin{array}{l}\text { Samuelson \& } \\
\text { Zeckhauser (1988) }\end{array}$ & $\begin{array}{l}\text { American MTurk } \\
\text { workers }\left(1^{\text {st }} \text { phase }\right. \\
\text { replication) }\end{array}$ & $\begin{array}{l}\text { American MTurk } \\
\text { workers }\left(2^{\text {nd }} \text { phase }\right. \\
\text { replication })\end{array}$ \\
\hline Sample size & See notes below & 301 & 309 \\
\hline Geographic origin & $\begin{array}{l}\text { The subjects were } \\
\text { students in economic } \\
\text { classes at Boston } \\
\text { University and Harvard } \\
\text { University. More than } \\
\text { three-quarters were } \\
\text { first-year MBA } \\
\text { students. }\end{array}$ & US American & US American \\
\hline Gender & Not available & 143 males, 158 females & 151 males, 158 females \\
\hline Median age (years) & Not available & 35 & 37 \\
\hline Average age (years) & Not available & 38.19 & 39.00 \\
\hline Age range (years) & Not available & $19-77$ & $20-70$ \\
\hline Medium (location) & $\begin{array}{l}\text { Paper (administered in- } \\
\text { class) }\end{array}$ & Computer (online) & Computer (online) \\
\hline Compensation & No & Nominal payment & Nominal payment \\
\hline Year & Around 1988 & 2017 & 2018 \\
\hline
\end{tabular}

Note. A total of 486 students participated in Samuelson and Zeckhauser's (1988) experiment (p. 14). Nonetheless, as there were also two-option and three-option versions of the decision questions in their study, the number of participants that went through the questions used in our replications was smaller. 


\section{Results after exclusion}

\section{First-phase replication}

Table 8S. Status quo vs. non-status quo ( $1^{\text {st }}$ phase; after exclusion $)$

\begin{tabular}{|c|c|c|c|c|c|c|c|}
\hline \multirow[b]{2}{*}{ Options } & \multicolumn{3}{|c|}{ Choice rates } & \multicolumn{4}{|c|}{ Status quo vs. non-status quo } \\
\hline & SQ & $\mathbf{N}$ & NSQ & $\chi^{2}$ & $p$ & $\begin{array}{l}\text { Odd ratio } \\
(95 \% \text { CI })\end{array}$ & $\begin{array}{l}\text { Cohen's } h \\
(95 \% \text { CI })\end{array}$ \\
\hline \multicolumn{8}{|l|}{ Scenario 1} \\
\hline $70 \mathrm{~A} 30 \mathrm{H}$ & $18 / 61(.30)$ & $5 / 63(.08)$ & $12 / 177(.07)$ & 21.27 & $<.001$ & $5.76[2.58,12.86]$ & $0.62[0.33,0.91]$ \\
\hline $30 \mathrm{~A} 70 \mathrm{H}$ & $30 / 57(.53)$ & $26 / 63(.41)$ & $45 / 181(.25)$ & 15.49 & $<.001$ & $3.36[1.81,6.24]$ & $0.58[0.28,0.88]$ \\
\hline $60 \mathrm{~A} 40 \mathrm{H}$ & $24 / 62(.39)$ & $10 / 63(.16)$ & $21 / 176(.12)$ & 21.44 & $<.001$ & $4.66[2.35,9.25]$ & $0.64[0.35,0.93]$ \\
\hline $50 \mathrm{~A} 50 \mathrm{H}$ & $31 / 58(.53)$ & $22 / 63(.35)$ & $57 / 180(.32)$ & 8.93 & .003 & $2.48[1.35,4.53]$ & $0.44[0.15,0.74]$ \\
\hline \multicolumn{8}{|l|}{ Scenario 2} \\
\hline Red & $8 / 60(.13)$ & $13 / 60(.22)$ & $24 / 181(.13)$ & 0.00 & .988 & $1.01[0.43,2.38]$ & $0.00[-0.29,0.29]$ \\
\hline Silver Blue & $35 / 60(.58)$ & $36 / 60(.60)$ & $106 / 181(.59)$ & 0.00 & .975 & $0.99[0.55,1.79]$ & $0.00[-0.30,0.29]$ \\
\hline Tan & 4/61 (.07) & $4 / 60(.07)$ & $12 / 180(.07)$ & 0.00 & .976 & $0.98[0.30,3.17]$ & $0.00[-0.29,0.29]$ \\
\hline White & $17 / 60(.28)$ & $7 / 60(.12)$ & $35 / 181(.19)$ & 2.16 & .142 & $1.65[0.84,3.23]$ & $0.21[-0.08,0.50]$ \\
\hline
\end{tabular}

Note. $\mathrm{SQ}=$ status quo, $\mathrm{N}=$ neutral, $\mathrm{NSQ}=$ non-status quo.

Table 9S. Status quo vs. neutral ( $1^{\text {st }}$ phase; after exclusion)

\begin{tabular}{|c|c|c|c|c|c|c|c|}
\hline \multirow[b]{2}{*}{ Options } & \multicolumn{3}{|c|}{ Choice rates } & \multicolumn{4}{|c|}{ Status quo vs. neutral } \\
\hline & SQ & $\mathbf{N}$ & NSQ & $\chi^{2}$ & $p$ & $\begin{array}{l}\text { Odd ratio } \\
(95 \% \text { CI })\end{array}$ & $\begin{array}{l}\text { Cohen's } h \\
\text { (95\% CI) }\end{array}$ \\
\hline \multicolumn{8}{|l|}{ Scenario 1} \\
\hline $70 \mathrm{~A} 30 \mathrm{H}$ & $18 / 61(.30)$ & $5 / 63(.08)$ & 12/177 (.07) & 9.55 & .002 & $4.86[1.67,14.11]$ & $0.58[0.23,0.93]$ \\
\hline $30 \mathrm{~A} 70 \mathrm{H}$ & $30 / 57(.53)$ & $26 / 63(.41)$ & $45 / 181(.25)$ & 1.55 & .213 & $1.58[0.77,3.26]$ & $0.23[-0.13,0.59]$ \\
\hline $60 \mathrm{~A} 40 \mathrm{H}$ & $24 / 62(.39)$ & $10 / 63(.16)$ & $21 / 176(.12)$ & 8.23 & .004 & $3.35[1.43,7.81]$ & $0.52[0.17,0.87]$ \\
\hline $50 \mathrm{~A} 50 \mathrm{H}$ & $31 / 58(.53)$ & $22 / 63(.35)$ & $57 / 180(.32)$ & 4.21 & .040 & $2.14[1.03,4.44]$ & $0.38[0.02,0.73]$ \\
\hline \multicolumn{8}{|l|}{ Scenario 2} \\
\hline Red & $8 / 60(.13)$ & $13 / 60(.22)$ & 24/181 (.13) & 1.44 & .230 & $0.56[0.21,1.46]$ & $-0.22[-0.58,0.14]$ \\
\hline Silver Blue & $35 / 60(.58)$ & $36 / 60(.60)$ & $106 / 181(.59)$ & 0.03 & .853 & $0.93[0.45,1.93]$ & $-0.03[-0.39,0.32]$ \\
\hline Tan & 4/61 (.07) & $4 / 60(.07)$ & $12 / 180(.07)$ & 0.00 & .981 & $0.98[0.23,4.12]$ & $0.00[-0.36,0.35]$ \\
\hline White & $17 / 60(.28)$ & $7 / 60(.12)$ & 35/181 (.19) & 5.21 & .022 & $2.99[1.14,7.88]$ & $0.43[0.07,0.78]$ \\
\hline
\end{tabular}

Note. $\mathrm{SQ}=$ status quo, $\mathrm{N}=$ neutral, $\mathrm{NSQ}=$ non-status quo. 


\section{Second-phase replication}

Table 10S. Status quo vs. non-status quo ( $2^{\text {nd }}$ phase; after exclusion)

\begin{tabular}{|c|c|c|c|c|c|c|c|}
\hline \multirow[b]{2}{*}{ Options } & \multicolumn{3}{|c|}{ Choice rates } & \multicolumn{4}{|c|}{ Status quo vs. non-status quo } \\
\hline & SQ & $\mathbf{N}$ & NSQ & $\chi^{2}$ & $p$ & $\begin{array}{l}\text { Odd ratio } \\
(95 \% \text { CI })\end{array}$ & $\begin{array}{l}\text { Cohen's } h \\
(95 \% \text { CI })\end{array}$ \\
\hline \multicolumn{8}{|l|}{ Scenario 1} \\
\hline $70 \mathrm{~A} 30 \mathrm{H}$ & $18 / 63(.29)$ & $7 / 61(.11)$ & $20 / 185(.11)$ & 11.43 & .001 & $3.30[1.61,6.76]$ & $0.46[0.17,0.74]$ \\
\hline $30 \mathrm{~A} 70 \mathrm{H}$ & $33 / 59(.56)$ & $10 / 61(.16)$ & $38 / 189(.20)$ & 28.24 & $<.001$ & $5.04[2.70,9.42]$ & $0.76[0.47,1.05]$ \\
\hline $60 \mathrm{~A} 40 \mathrm{H}$ & $25 / 63(.40)$ & $13 / 61(.21)$ & $35 / 185(.19)$ & 11.05 & .001 & $2.82[1.51,5.27]$ & $0.46[0.18,0.75]$ \\
\hline $50 \mathrm{~A} 50 \mathrm{H}$ & $40 / 63(.63)$ & $31 / 61(.51)$ & $36 / 122(.30)$ & 19.82 & $<.001$ & $4.15[2.18,7.91]$ & $0.70[0.39,1.00]$ \\
\hline \multicolumn{8}{|l|}{ Scenario 2} \\
\hline Red & $18 / 59(.31)$ & $15 / 64(.23)$ & 23/186 (.12) & 10.58 & .001 & $3.11[1.54,6.30]$ & $0.45[0.16,0.74]$ \\
\hline Silver Blue & $33 / 65(.51)$ & $30 / 64(.47)$ & $98 / 180(.54)$ & 0.26 & .611 & $0.86[0.49,1.52]$ & $-0.07[-0.36,0.21]$ \\
\hline Tan & $10 / 60(.17)$ & $5 / 64(.08)$ & $15 / 185(.08)$ & 3.62 & .057 & $2.27[0.96,5.36]$ & $0.26[-0.03,0.55]$ \\
\hline White & $11 / 61(.18)$ & $14 / 64(.22)$ & $37 / 184(.20)$ & 0.13 & .723 & $0.87[0.41,1.84]$ & $-0.05[-0.34,0.24]$ \\
\hline \multicolumn{8}{|l|}{ Scenario 3} \\
\hline Mod. Risk & $22 / 63(.35)$ & $14 / 60(.23)$ & $43 / 186(.23)$ & 3.40 & .065 & $1.78[0.96,3.32]$ & $0.26[-0.02,0.55]$ \\
\hline High Risk & $7 / 62(.11)$ & $7 / 60(.12)$ & $16 / 187(.09)$ & 0.42 & .519 & $1.36[0.53,3.48]$ & $0.09[-0.20,0.38]$ \\
\hline Treasury & $35 / 61(.57)$ & $25 / 60(.42)$ & $79 / 188(.42)$ & 4.38 & .036 & $1.86[1.04,3.33]$ & $0.31[0.02,0.60]$ \\
\hline Municipal & $21 / 63(.33)$ & $14 / 60(.23)$ & $26 / 186(.14)$ & 11.51 & .001 & $3.08[1.58,6.00]$ & $0.46[0.18,0.75]$ \\
\hline \multicolumn{8}{|l|}{ Scenario 4} \\
\hline College A & $16 / 62(.26)$ & $10 / 61(.16)$ & 15/186 (.08) & 13.38 & $<.001$ & $3.97[1.82,8.62]$ & $0.49[0.20,0.78]$ \\
\hline College B & $33 / 63(.52)$ & 23/61 (.38) & $42 / 185(.23)$ & 19.62 & $<.001$ & $3.75[2.05,6.84]$ & $0.63[0.34,0.91]$ \\
\hline College C & $35 / 62(.56)$ & 18/61(.30) & $41 / 186(.22)$ & 25.90 & $<.001$ & $4.58[2.49,8.44]$ & $0.72[0.44,1.01]$ \\
\hline College D & $22 / 61(.36)$ & $10 / 61(.16)$ & $44 / 187(.24)$ & 3.70 & .054 & $1.83[0.98,3.42]$ & $0.28[-0.01,0.56]$ \\
\hline
\end{tabular}

Table 11S. Status quo vs. neutral ( $2^{\text {nd }}$ phase; after exclusion)

\begin{tabular}{|c|c|c|c|c|c|c|c|}
\hline \multirow[b]{2}{*}{ Options } & \multicolumn{3}{|c|}{ Choice rates } & \multicolumn{4}{|c|}{ Status quo vs. neutral } \\
\hline & SQ & $\mathbf{N}$ & NSQ & $\chi^{2}$ & $p$ & $\begin{array}{l}\text { Odd ratio } \\
(95 \% \text { CI })\end{array}$ & $\begin{array}{l}\text { Cohen's } h \\
\text { (95\% CI) }\end{array}$ \\
\hline \multicolumn{8}{|l|}{ Scenario 1} \\
\hline $70 \mathrm{~A} 30 \mathrm{H}$ & $18 / 63(.29)$ & $7 / 61(.11)$ & $20 / 185(.11)$ & 5.63 & .018 & $3.09[1.18,8.05]$ & $0.44[0.08,0.79]$ \\
\hline $30 \mathrm{~A} 70 \mathrm{H}$ & $33 / 59(.56)$ & $10 / 61(.16)$ & $38 / 189(.20)$ & 20.39 & $<.001$ & $6.47[2.76,15.15]$ & $0.86[0.50,1.21]$ \\
\hline $60 \mathrm{~A} 40 \mathrm{H}$ & $25 / 63(.40)$ & $13 / 61(.21)$ & $35 / 185(.19)$ & 4.92 & .027 & $2.43[1.10,5.37]$ & $0.40[0.05,0.76]$ \\
\hline $50 \mathrm{~A} 50 \mathrm{H}$ & $40 / 63(.63)$ & $31 / 61(.51)$ & $36 / 122(.30)$ & 2.03 & .154 & $1.68[0.82,3.45]$ & $0.26[-0.10,0.61]$ \\
\hline \multicolumn{8}{|l|}{ Scenario 2} \\
\hline Red & $18 / 59(.31)$ & $15 / 64(.23)$ & $23 / 186(.12)$ & 0.78 & .377 & $1.43[0.64,3.19]$ & $0.16[-0.19,0.51]$ \\
\hline Silver Blue & $33 / 65(.51)$ & $30 / 64(.47)$ & $98 / 180(.54)$ & 0.20 & .658 & $1.17[0.59,2.33]$ & $0.08[-0.27,0.42]$ \\
\hline Tan & $10 / 60(.17)$ & $5 / 64(.08)$ & $15 / 185(.08)$ & 2.28 & .131 & $2.36[0.76,7.36]$ & $0.27[-0.08,0.63]$ \\
\hline White & $11 / 61(.18)$ & $14 / 64(.22)$ & $37 / 184(.20)$ & 0.29 & .591 & $0.79[0.33,1.90]$ & $-0.10[-0.45,0.25]$ \\
\hline \multicolumn{8}{|l|}{ Scenario 3} \\
\hline Mod. Risk & $22 / 63(.35)$ & $14 / 60(.23)$ & $43 / 186(.23)$ & 1.99 & .158 & $1.76[0.80,3.89]$ & $0.26[-0.10,0.61]$ \\
\hline High Risk & $7 / 62(.11)$ & $7 / 60(.12)$ & $16 / 187(.09)$ & 0.00 & .948 & $0.96[0.32,2.93]$ & $-0.01[-0.37,0.34]$ \\
\hline Treasury & $35 / 61(.57)$ & $25 / 60(.42)$ & $79 / 188(.42)$ & 2.99 & .084 & $1.88[0.92,3.88]$ & $0.32[-0.04,0.67]$ \\
\hline Municipal & $21 / 63(.33)$ & $14 / 60(.23)$ & $26 / 186(.14)$ & 1.51 & .219 & $1.64[0.74,3.64]$ & $0.22[-0.13,0.58]$ \\
\hline \multicolumn{8}{|l|}{ Scenario 4} \\
\hline College A & $16 / 62(.26)$ & $10 / 61(.16)$ & 15/186 (.08) & 1.63 & .201 & $1.77[0.73,4.30]$ & $0.23[-0.12,0.59]$ \\
\hline College B & $33 / 63(.52)$ & $23 / 61(.38)$ & $42 / 185(.23)$ & 2.70 & .101 & $1.82[0.89,3.72]$ & $0.30[-0.06,0.65]$ \\
\hline College C & $35 / 62(.56)$ & $18 / 61(.30)$ & $41 / 186(.22)$ & 9.10 & .003 & $3.10[1.47,6.52]$ & $0.55[0.20,0.91]$ \\
\hline College D & $22 / 61(.36)$ & $10 / 61(.16)$ & $44 / 187(.24)$ & 6.10 & .014 & $2.88[1.22,6.77]$ & $0.45[0.10,0.81]$ \\
\hline
\end{tabular}

Note. $\mathrm{SQ}=$ status quo, $\mathrm{N}=$ neutral, $\mathrm{NSQ}=$ non-status quo. 


\section{Replication evaluation}

Figure 1S. Criteria for evaluation of replication results

A Signal Detected in Original Study

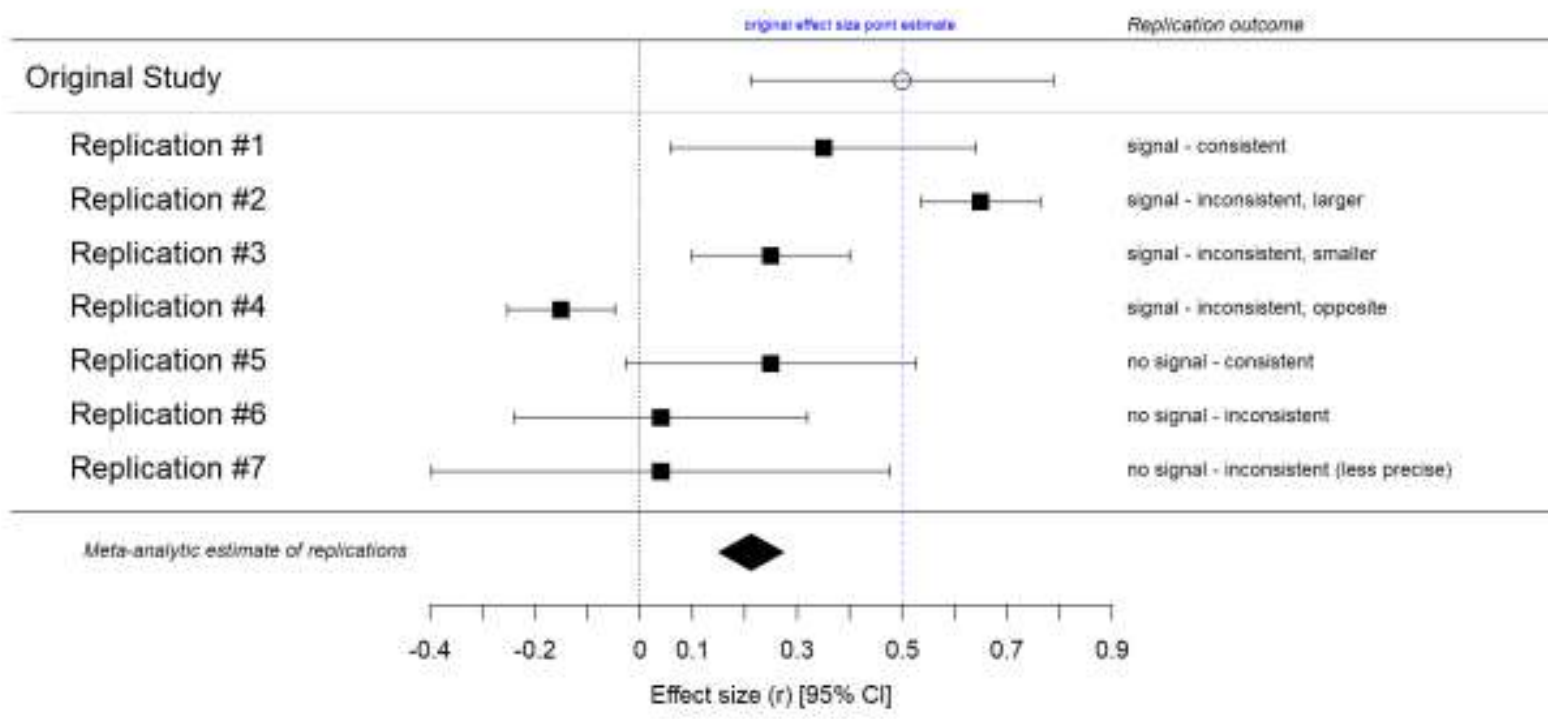

B Signal Not Detected in Original Study

Original Study
Replication \#1
Replication \#2
Replication \#3
Replication \#4 \#5

A simplified taxonomy for comparing replication effects to original findings by LeBel et al. (2019). 
Figure 2S. Criteria for evaluation of replications

\begin{tabular}{|c|c|c|c|c|c|}
\hline $\begin{array}{r}\text { Target similarity } \\
\text { Category }\end{array}$ & $\begin{array}{l}\text { Highly similar } \\
\text { Direct replication }\end{array}$ & & & \multicolumn{2}{|c|}{ Conceptual replication } \\
\hline Design facet & $\begin{array}{c}\text { Exact } \\
\text { replication }\end{array}$ & $\begin{array}{l}\text { Very close } \\
\text { replication }\end{array}$ & $\begin{array}{c}\text { Close } \\
\text { replication }\end{array}$ & Far replication & $\begin{array}{l}\text { Very far } \\
\text { replication }\end{array}$ \\
\hline Effect, Hypothesis & Same/similar & Same/similar & Same/similar & Same/similar & Same/similar \\
\hline IV Construct & Same/similar & Same/similar & Same/similar & Same/similar & Different \\
\hline DV Construct & Same/similar & Same/similar & Same/similar & Same/similar & Different \\
\hline IV Operationalization & Same/similar & Same/similar & Same/similar & Different & \\
\hline DV Operationalization & Same/similar & Same/similar & Same/similar & Different & \\
\hline Population (e.g., age) & Same/similar & Same/similar & Same/similar & Different & \\
\hline IV Stimuli & Same/similar & Same/similar & Different & & \\
\hline DV Stimuli & Same/similar & Same/similar & Different & & \\
\hline Procedural Details & Same/similar & Different & & & \\
\hline Physical Setting & Same/similar & Different & & & \\
\hline Contextual Variables & Different & & & & \\
\hline
\end{tabular}

Criteria for evaluation of replications by LeBel et al. (2018). A classification of relative methodological similarity of a replication study to an original study. "Same" ("different") indicates the design facet in question is the same (different) compared to an original study. IV = independent variable. DV = dependent variable. "Everything controllable" indicates design facets over which a researcher has control. Procedural details involve minor experimental particulars (e.g., task instruction wording, font, font size, etc.). "Similar" category was added to the Lebel et al. (2018) typology to refer to minor deviations aimed to adjust the study to the target sample that are not expected to have major implications on replication success.

Table 12S. Classification of the replications based on LeBel et al. (2018)

\begin{tabular}{ll}
\hline Design facet & Replication \\
\hline Effect, Hypothesis & Same \\
IV Construct & Same \\
DV Construct & Same \\
IV Operationalization & Same \\
DV Operationalization & Same \\
Population (e.g., age) & Similar \\
IV Stimuli & Similar \\
DV Stimuli & Same \\
Procedural Details & Similar \\
Physical Setting & Different \\
Contextual Variables & Different \\
\hline Replication classification & Very close replication \\
\hline
\end{tabular}




\section{Error documentation}

We identified an error in our questionnaire after the data collection. In Scenario 1 of the second-phase replication, the option "allocating $50 \%$ of the budget to auto safety and $50 \%$ budget to highway safety" was not present in the condition where " $70 \%$ to auto safety and $30 \%$ to highway safety" was the status quo option (please refer to page 11 of the questionnaire in .docx format). What was presented instead was essentially an option to allocate $90 \%$ budget to auto safety and $10 \%$ budget to highway safety, and as the result, the 50A50H option had one fewer NSQ condition. We excluded this part of the data in our analysis. 


\section{References}

Cohen, J. (1988). Statistical power analysis for the behavioral sciences (2nd ed.). L. Erlbaum Associates.

LeBel, E. P., McCarthy, R. J., Earp, B. D., Elson, M., \& Vanpaemel, W. (2018). A unified framework to quantify the credibility of scientific findings. Advances in Methods and Practices in Psychological Science, 1(3), 389-402. https://doi.org/10.1177/2515245918787489

LeBel, E. P., Vanpaemel, W., Cheung, I., \& Campbell, L. (2019). A brief guide to evaluate replications. Meta-Psychology, 3. https://doi.org/10.15626/MP.2018.843

Samuelson, W., \& Zeckhauser, R. (1988). Status quo bias in decision making. Journal of Risk and Uncertainty, 1(1), 7-59. https://doi.org/10.1007/BF00055564 